\title{
أدب الحوار مع المخالفين من خلال السنة النبوية
}

اعلدد: د. عبله أحمل فضل السيل فضل الله

أستاذ الحليث المساعل بجامعة القرآن الكريه

والعلوم الإسلامية. السودان. وجامعلة المجمعة. السعودية

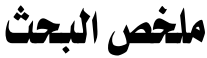

فهما لا شك فيه أن الاختلاف قضيـة لابد مـ حدوثها وأن المخررج مـن هذا الاختلاف هو الحوار وإقامـة الحجة، والمتأهل في سنـة النبوية يجد أنها

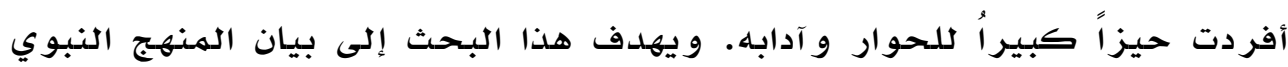
في الحوار مـع المـخالف، سواء كان هذا المـخالف منتسبب لأهل السنـة و الجمـاعة خاصدة الحوار حال نشوب الخلافات بينهه، والحوار في حال التخاصدم والتنازع، كما تناول البحث الحوار مـع الهـخالف الهنتسب لأهل البدع، ومن ذلك حوار النبي- صدلى الله عليه وسلهم لأحد الخوارج، وحور ابن عباس رضي الله عنه للخوارج، وتناول البحث كذلك حوار المـخالف غير المسلهم، مثل حوار النبي صلى الله عليه و سلهم لهشركي مكهة، وحواره لليهود والنصارى، كما تناول البحث بعض الآداب التي ينبغي مر اعاتها في الحوار، وومن ذلك اخلاص النيـة لله عز وجل، والتسـلح بالعلهم، وحسن الاستمـاع وتجنب المقاطعة و العدل و الانصاف، و ضبط النفس، و استخلدم البـاحث في الدراسـة الهنهج الوصفي التحليلي، مـع العزو و الإحالة والتخريج المتبعة في منهجية البحث العلهي، وتوصل الباحث إلى أنه لابد لأهل الإسـلام أن يقتدوا بالنببي صلى الله عليه و سلهم ويتأسوا بـه في الحوار، و أن ترك النـاس لآداب الحوار التي كان يتبعها النبي صدلى الله عليه وسلهم أدى إلى النتائج التي نراها اليوم مـن عنف وتكفير وغير ذلك، وأن الحوار ينبغي أن تكون الغاية منـه الوصول إلى الحق، و أن الحوار مـع الهـخالف لله قواعد ضوابط

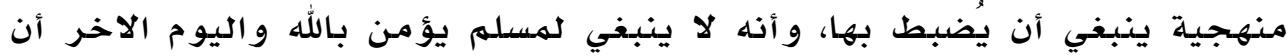
يقدم على تكفير الناس إلا ببرهان أوضتح من الشهس، وأن الهـحاور عليه أن يتحلى بالصبـر وأن لا يستعجل النتائج، وأنه ينبغي للهـحاور أن يتسلح بالعلهم و أن لا يتحاور في موضوع لا يعرفه، و أن لا يدافع عن فكرة غير مقتنـع بها.

الكلمات المفتاحية: أدب - الحوار - المخالف - السنة النبوية 


\title{
The Etiquette of Dialogue with the Counterpart Through the Prophetic
}

\section{Sunnah}

\begin{abstract}
There is no doubt that difference is an issue that must occur and its solution is through dialogue ,and the establishment of an argument .If someone looks at the Prophetic Sunnah, he will find that, it has devoted a great deal of space to the dialogue and its etiquette for its significance. This study aims to explain the prophetic approach in dialogue with the contrary part ' whether he is associated with the Sunnis groups, especially in case of dialogue eruption due to differences between them, or the dialogue in the event of wrangle and conflict. As well as discussing dialogue with the counterpart that is associated with the people of Bidaa, (Those who deviates from the right way) including the dialogue of the (Prophet- peace be upon him) with one of the Kharijites. Ibn Abbas, may God bless him, also conducted a dialogue with the Kharijites. The study also addressed the dialogue of non-Muslim flip side, such as the Prophet's Dialogue with Mecca's Heathens, and his dialogue with the Jews and Christians. The study, also addressed some of the ethics that should be put into consideration in the dialogue, including the dedication of the intention to Allah Almighty, and the empowerment with knowledge, good listening, avoid boycotting, maintain justice, fairness, and selfdiscipline. The study used the descriptive analytical method, with the attribution, referral and citations followed in the scientific research methodology. The study arrives to the following findings:

1.Muslims must follow the prophet and take him as a role model in the dialogue.

$r$. The consequences of not sticking to the etiquettes of dialogue that founded by the Prophet (Peace be upon him), led to the violence and atonement that we see nowadays.

$r$.The main purpose of dialogue, is to reveal the truth, then the dialogue with the counterpart has certain rules and conditions, that should be followed.

₹.The real Muslim, who believes in God and the resurrection day should not accuse others by atonement, except with more proof as clear as sun.

0 .The interlocutor should be patient and doesn't haste for the results, moreover, he should be equipped with knowledge and shouldn't talk about a subject he doesn't know, beside avoid defending an idea that he doesn't know.
\end{abstract}

Keywords: Etiquette - Dialogue - The counterpart - The Prophetic Sunnah 
الحمدل لله رب العالمين، والصدلاة والسدلام على أشرف الهـرسلين، سيدنا محمد و على آله و صدحبـه أجمعين، أما بعد:

فمها لا شك فيه أن الاختلاف قضية لابد من حدوثها و أن المـخرج من هذا الاختلاف هو الحوار وإقامـة الحجة، لذلك هو أسلوب نبوي أصيل حافظ عليه النبي صلى الله عليه وسلهم فكان يحاور أصناف المخالفين من يهود وذنصارى

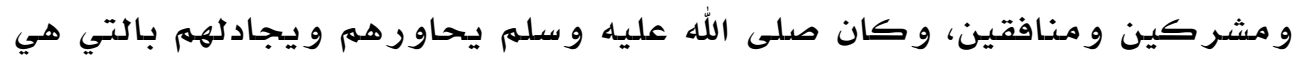

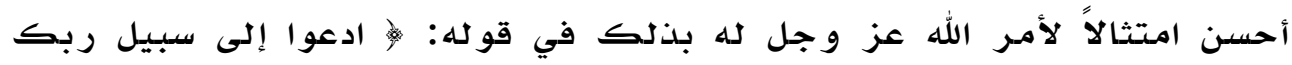

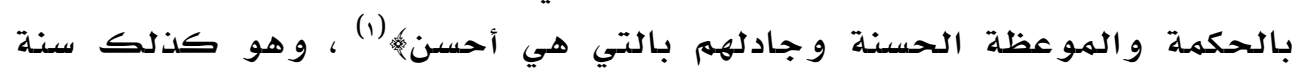
إلهية، وفطرة فطر عليها خلقه، وسار عليها أنبيائه صلوات الله عليهم فكانوا

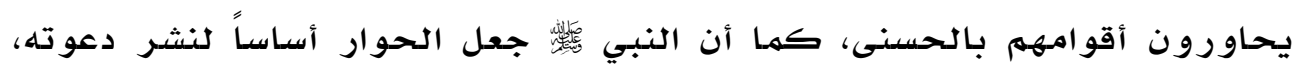
فكان يخرج إلى الناس يكلههم ويحاورهم، والناظر في سيرته صلى الله عليه و سلهم يجدها ناطقة بذلك وشاهدة بـه ولها ترك كل الناس هديه صلى الله عليه و سلهم في الحوار مـع المـخالفين، ظهرت الدعاوي البـاطلة والحهوارات الهـهلكة التي أدت إلى تكفير المهخالف والقسوة عليه في الحوار، وومن هنا تكمن أهمية هذا البـحث.

و لقد أطلعت على بعض البحوث والكتب التي كتبت في هذا المـجال فاستفدت منها أيما فائدة و مـن هذه الكتب: - فقه الحوار مـع الهـخالف في السنـة النبويـة، تأليف: فتحي عبد الله الهو صدلي

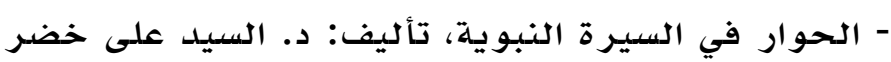
و غير ها مـن المو ضوعات التي كتبـت في هذا المـجال.

و قد بذلت بعض الجهد في إبراز آداب الحوار مـع المخحالف من خلال

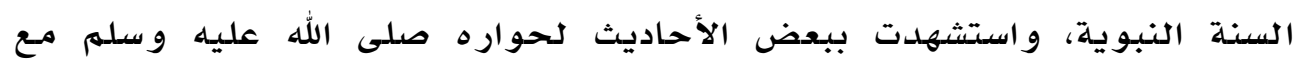
مشر كي مكة واليهود و النصارى، وكذلك ذهرت بعض الأمثلة لحوار أهل السنة و أهل البدعة، وذكرت كذلك بعض الآداب التي ينبغي أن يتصف بها المـحاور، سـائلاً الله عز وجل أن ينفع بـه كل من اطلع عليه، وأن يكتب لنا ذلك 
في ميزان حسناتنا إنه ولي ذلك والقادر عليه. وقد قسمت هذا البحث إلى مقدمة وخمسلة مباحث و هي كالاتي:

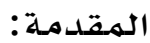

المبسحث الأو ل: مفاهيه البحث: وتحته ثلاثة مطالب:

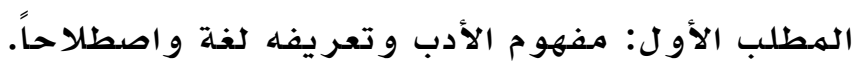
المطلب الثاني: مفهوم الحوار و تعريفه لغة و اصطلاحًا. الهـلب الثالث: المقصود بالمهخالف في هذا البـحث المبحث الثاني: حوار المـخالف المنتسب لأهل السنـة و الجماعة: وتحته ثلاثة مطادب:

المطلب الأو ل: الحوار حال نشوب الخلافات بينهم. المطلب الثاني: الحوار في حال التخاصدم والنزاع. المطلب الثالث: أن هذه الخلافات لا تؤدي إلى تكفير بعضهم البعض. المبحث الثالث: حوار المهخالف المنتسب لأهل البـل ع: و تحته مطالبـان: الهطلب الأول: حوار النبي صدلى الله عليه وسلهم لأحد الخوارج. المطلب الثاني: حوار ابن عباس رضي الله عنه للخوارج. الهبحث الرابع: حوار المهخالف غير الهسلهم: وتحته خمسلة مطالب: الهـلب الأول: حوار النبي صلى الله عليه و سلهم لهشر كي مكة. الهـلب الثاني: حوار النبي صلى الله عليه و سلهم لليهود. الهطلب الثالث: حوار النبي صلى الله عليه وسلهم للنصسارى. المبحث الخـامس: بعض الآداب التي ينبغي مـر اعاتها في الحوار: وتحتهل خمسـة مطادب: الهطلب الأو ل: إخلاص النية لله عز وجل.

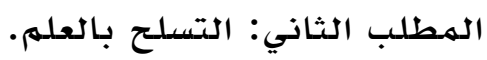
المطلب الثالث: حسن الاستهماع و تجنب المقاطعة. المطلب الر ابع: العدل و الإنصاف. المطلب الخامس: ضبط النفس. الخحاتمهة: النتائج و التو صيات: الفهارس: 


\section{المبحث الأول: مفاهيي البحث \\ المطلب الأول: مفهوم الأدب وتصريفه لغلة واصطلاحاً.}

مها لا شك فيه أن العلاقات بين الناس من أكثر الأمور دقولة وقة، و أصعبها

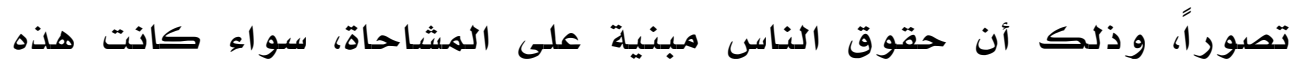

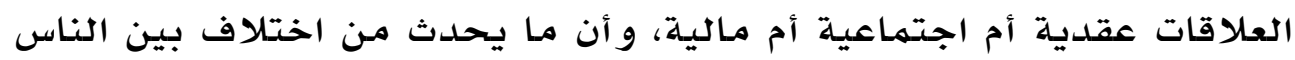

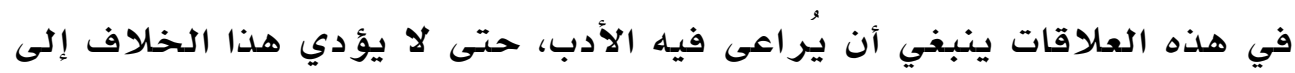

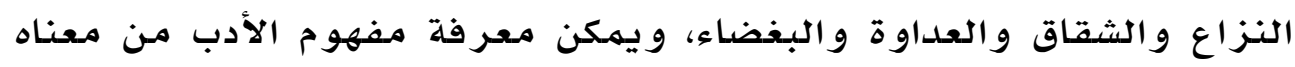

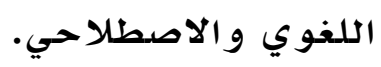

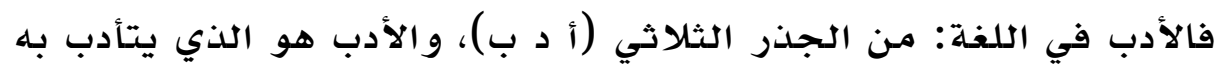

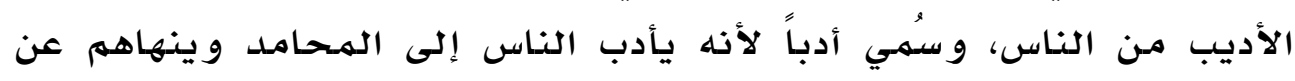

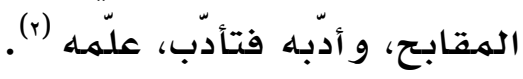

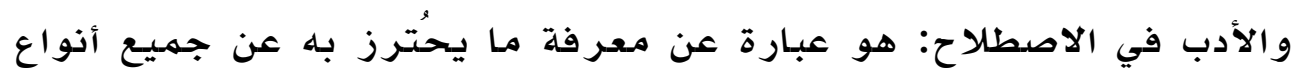

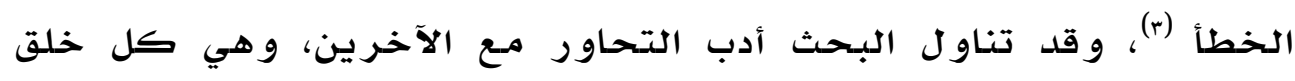

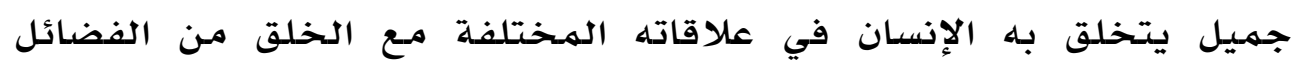
و السجايا المسحمودة.

\section{المطلب الثاني: مفهوم الحواروتصريفه لفة واصطالاحا.}

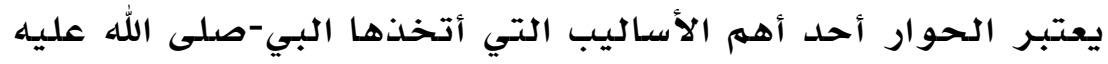

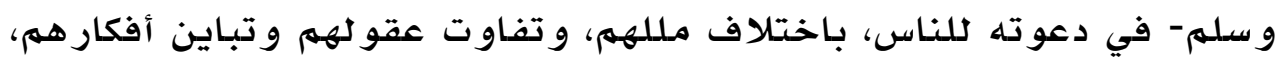

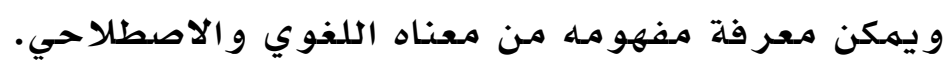

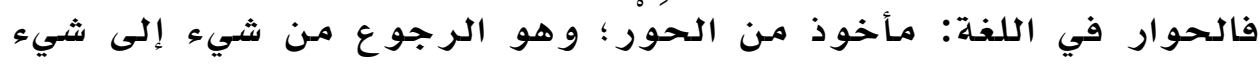

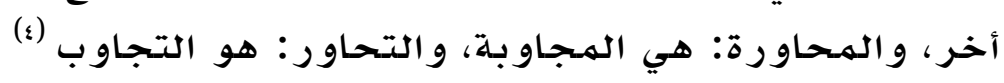

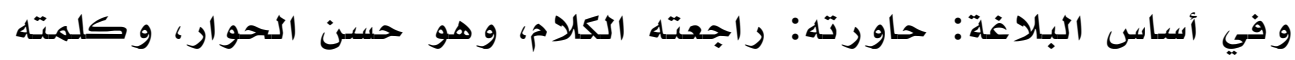

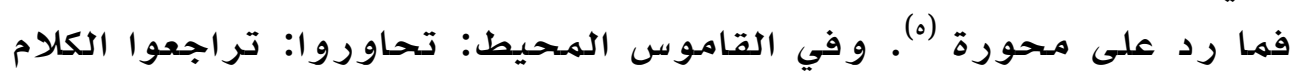

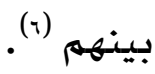
و الحوار هو: الهـرادّة في الكلام، وومنه التحسـاور فيقــال: كلهته فها

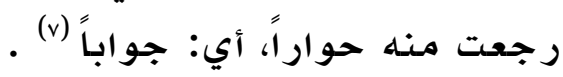




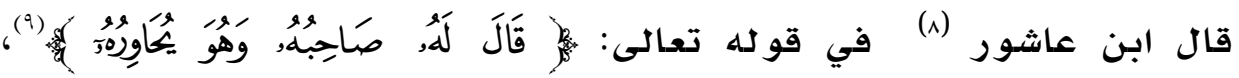
الهـحاورة: مر اجعة الكلام بين متكلمسين، ودل فعل الهـحاورة على أن صاحبـه

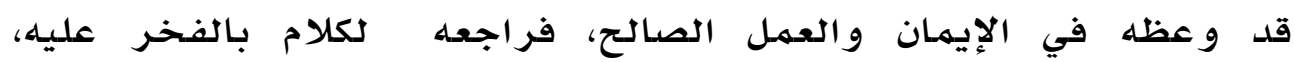

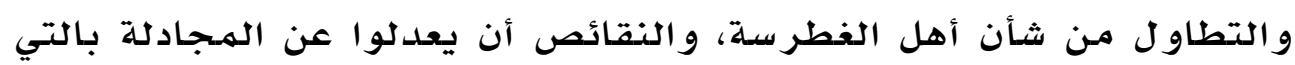

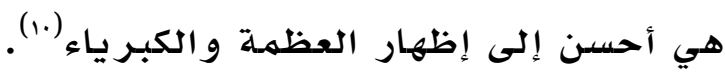

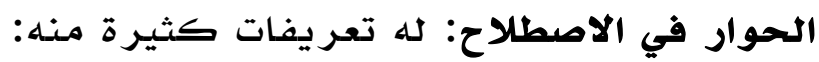

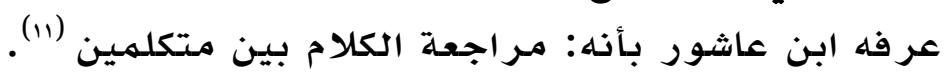

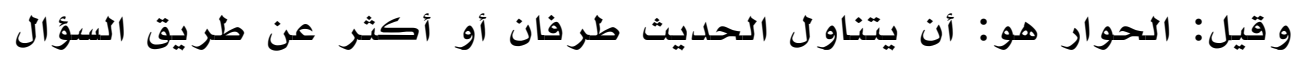

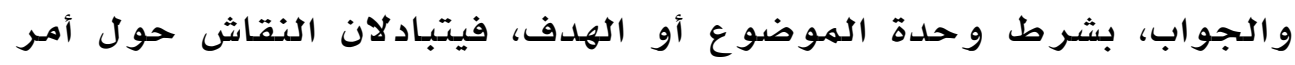

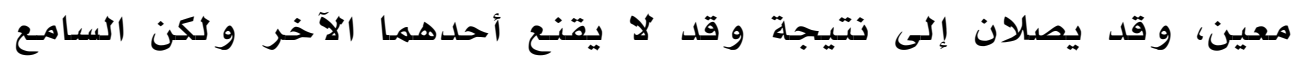

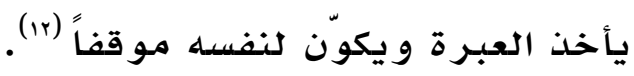

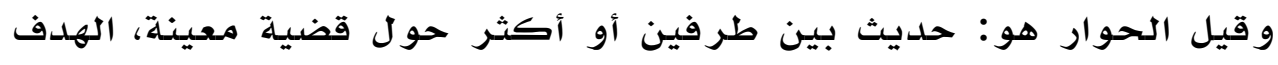

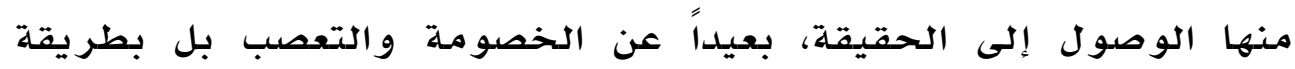

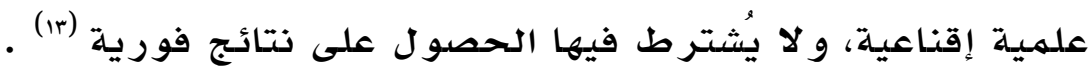

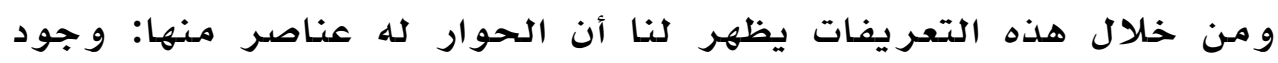

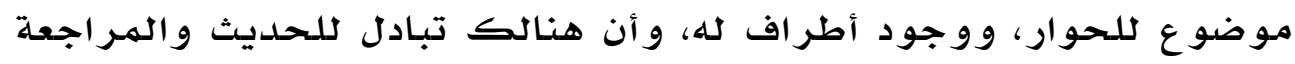

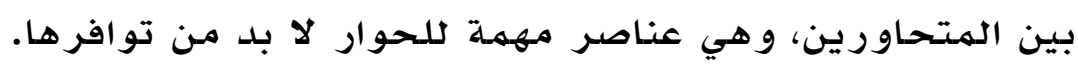
الالطلب الثالث: المقصود بالمخاونف في هلدا البحث:

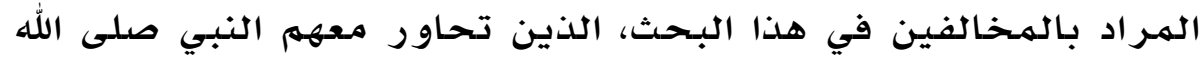

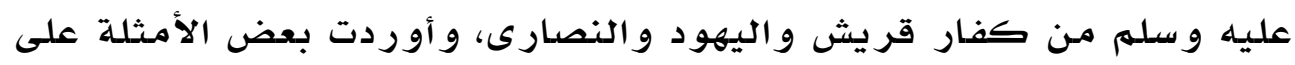

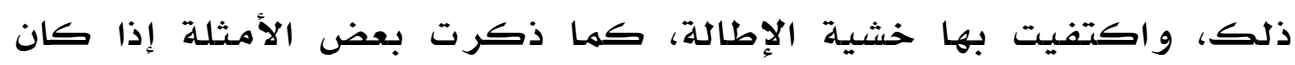

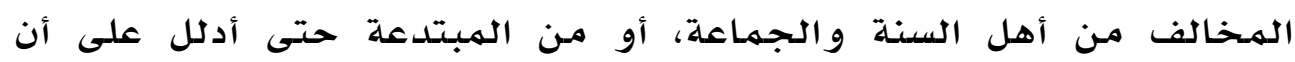

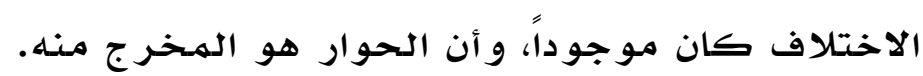
$\square$ 
المبحث الثاني: حوار المخالف المنتسب لأهل السنة والجماعلة

الأطلب الأول: الحوار حال ششوب الخلافات بينهم.

وجود الخلافات بين المسلمين في بعض شؤون الحياة أمر وارد الها لا شيء

فيه، و لا يزال الناس يختلفون منذ القدم إلى يومنا هذا، فيكون التحاور

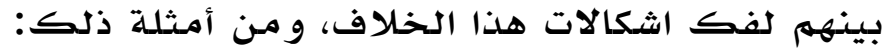

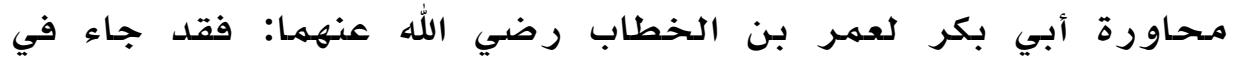

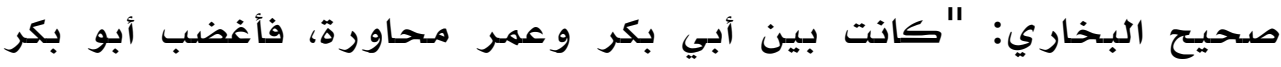
عمر فانصرف عنه عمر مغضباً، فاتبعه أبو بكر يسأله أن يستغفر لـورة له، فلهم يفعل حتى أغلق بابه في وجهه، فأقبل أبو بكر إلى رسول الله بهر صلى اللى الله

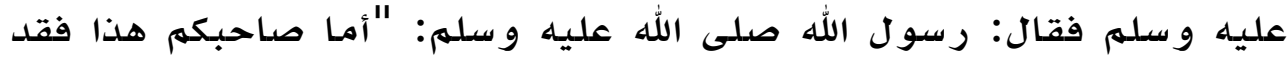

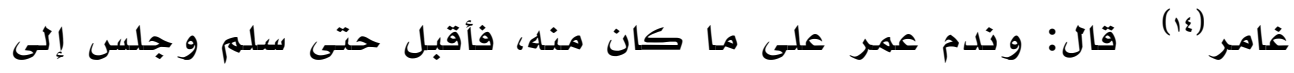
النبي صلى الله عليه وسلهم، وقص على رسول الله صلى الله عليه وسلهم

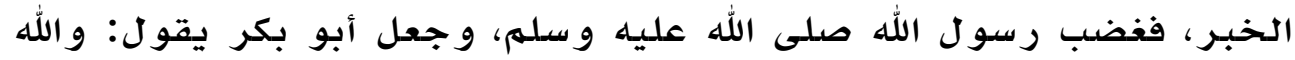

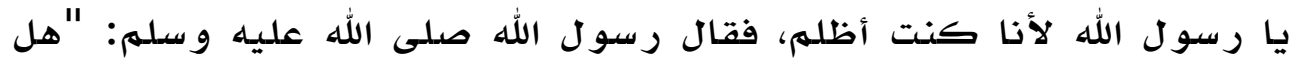
أنتم تاركون لي صاحبي، هل أنتم تاركون لي صاحبي، إني قلت: يأيها

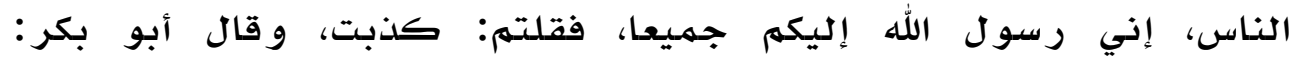

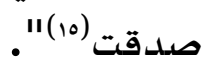

و الحديث دل على أنه يمكن أن يقع الخلاف بين أهل السنة، و أنه لا

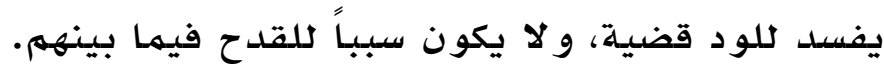

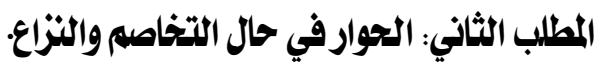
من طبيعة البشر وقوع التنازع و التخاصهم بينهم في أمور الحياة

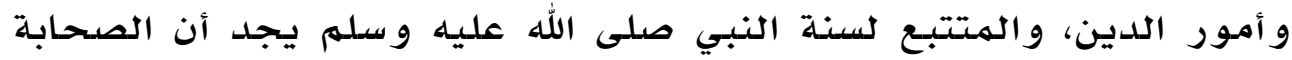

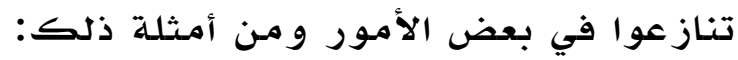

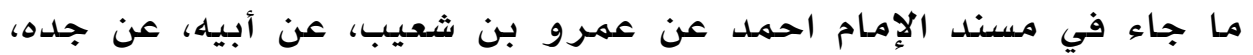

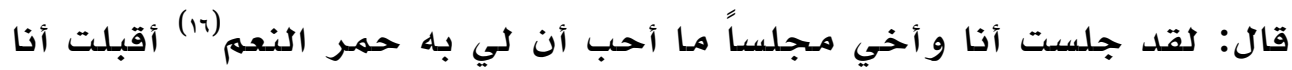

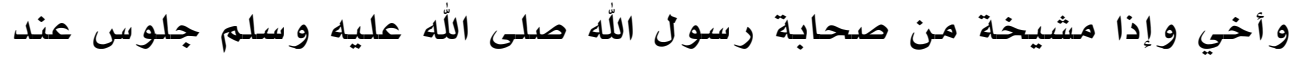

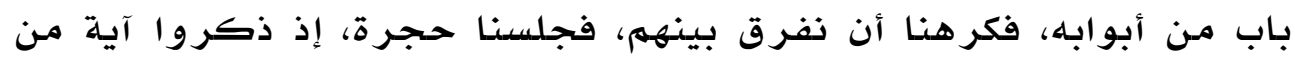

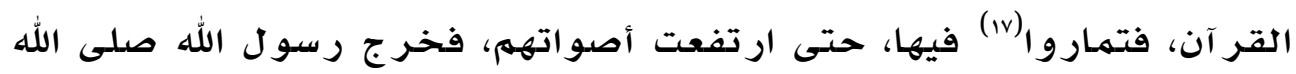




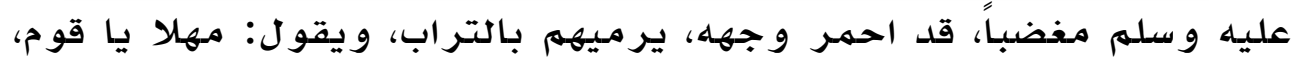

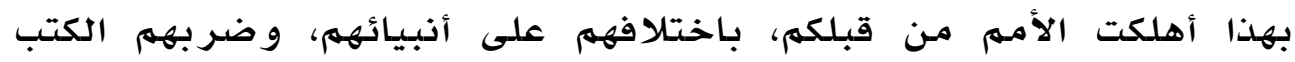

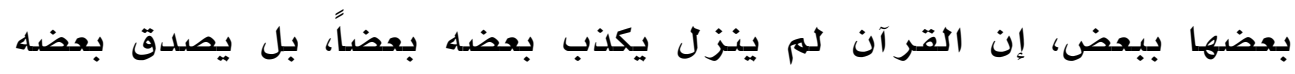

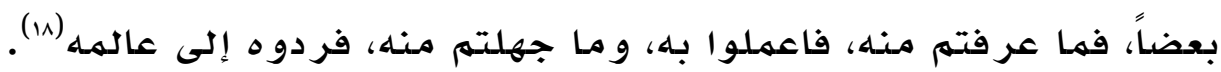

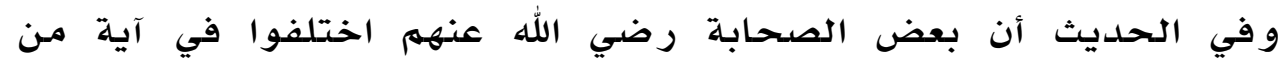

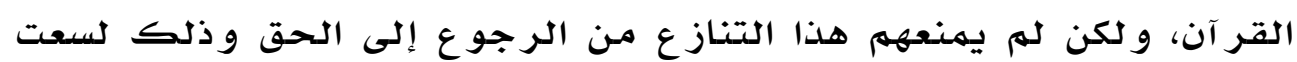

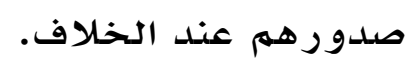

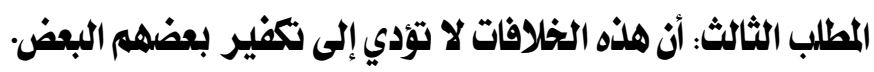

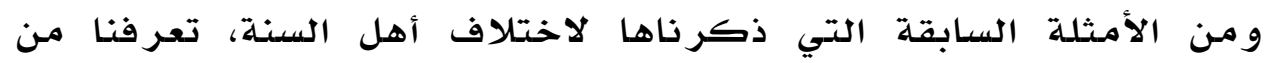

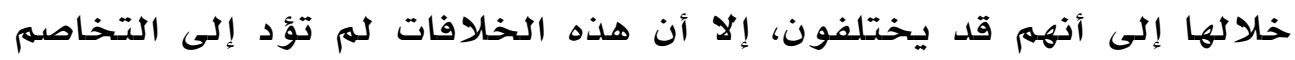

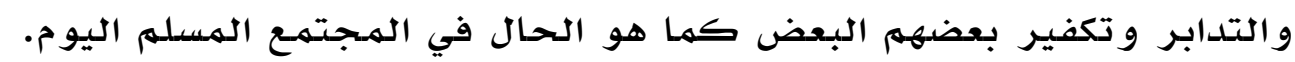

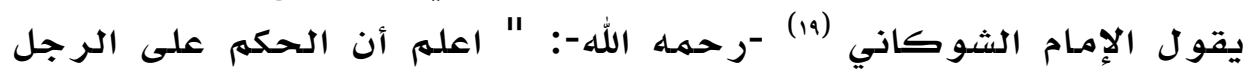

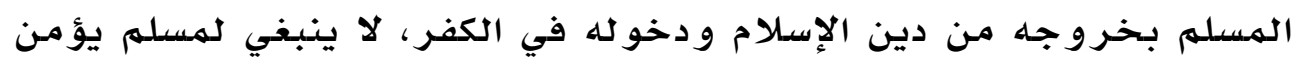

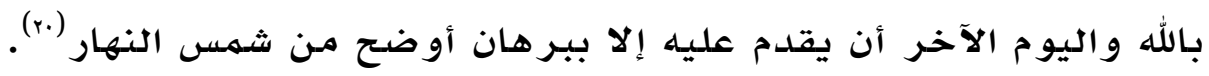




\section{المبحث الثالث: حوار المخالف المنتسب لأهل البلدع}

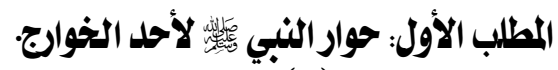

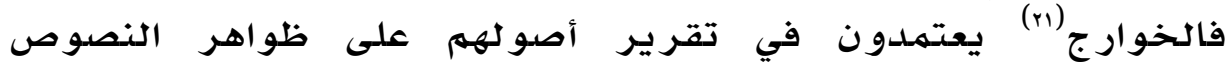

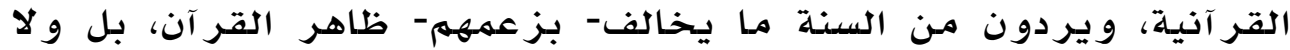

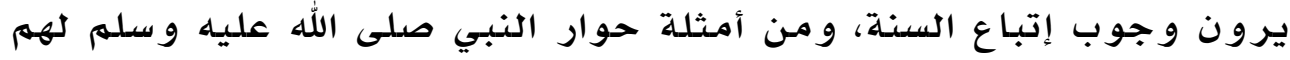

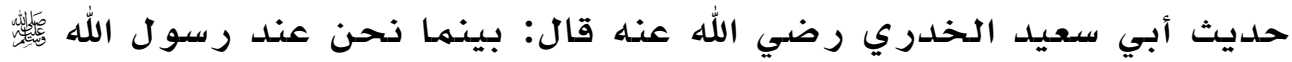

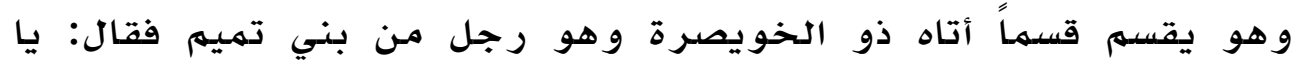

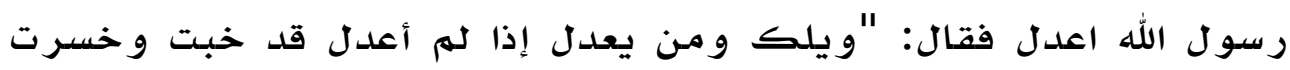

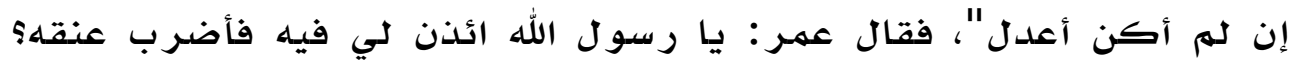

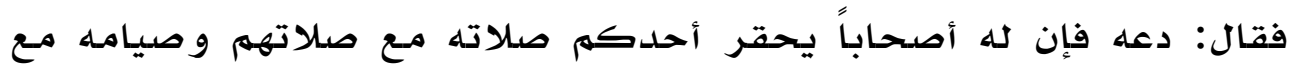

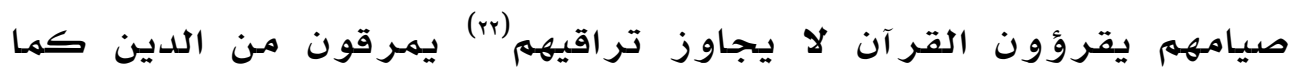

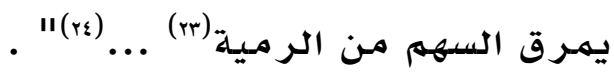

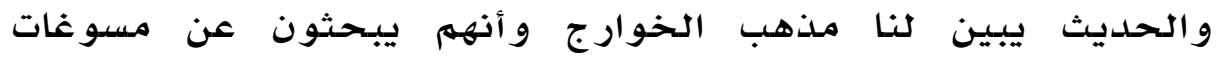

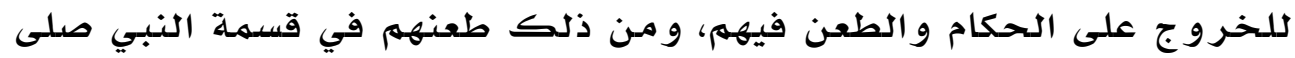

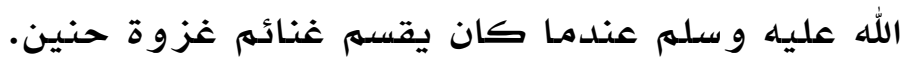

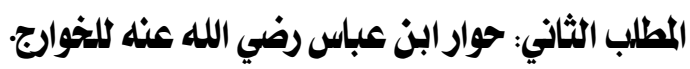

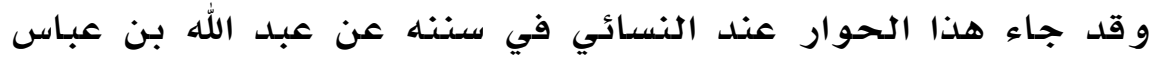

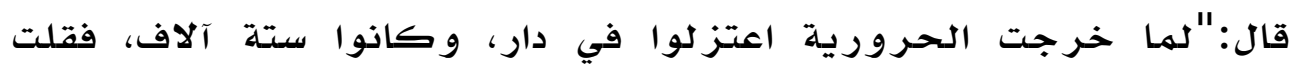

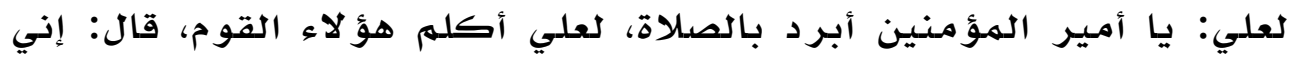

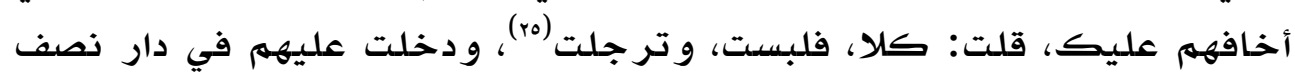

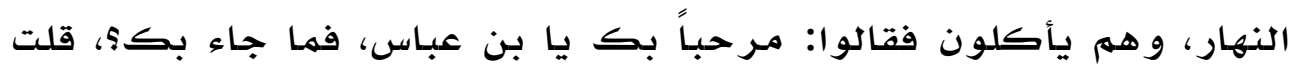

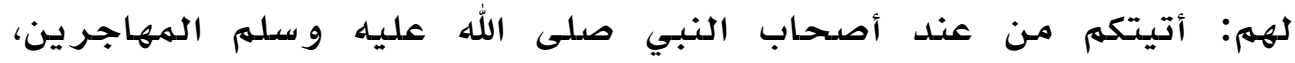

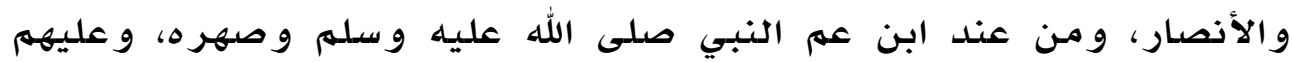

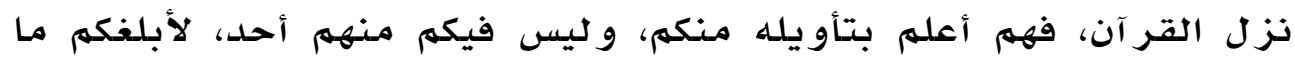

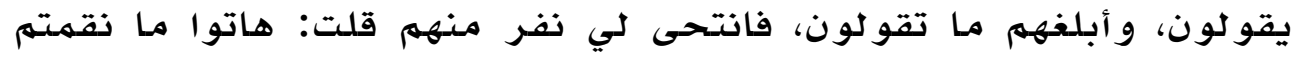

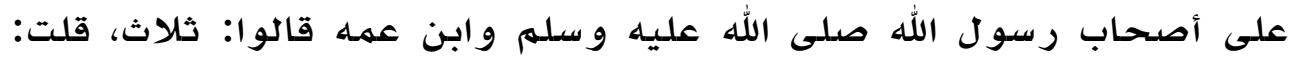

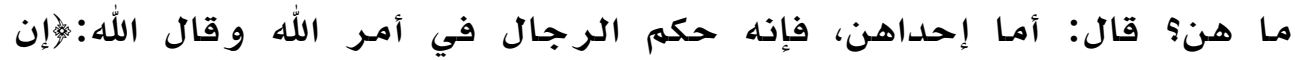

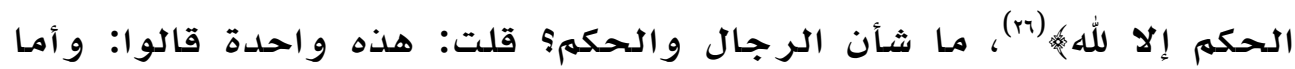


انثانية، فإنه قاتل، وله يسب، ولهم يغنهم، إن كانوا كفارا لقد حل سباهم، و لئن كانوا مؤمنين مـا حل سباهمر و لا قتالههم قلت: هذه ثنتان، فها الثالثة؟ "و ذكر كلمهة معناها قالوا: محىى نفسه من أمير الهؤمنين، فإن له يكن أمير الهؤمنين، فهو أمير الكافرين" قلت: هل عندكم شيء غير هذاي قالوا: حسبنا هذا، قلت: لهم أرأيتكم إن قرأت عليكمم مـن كتاب الله جل أله ثناؤه وسنـة نبيه ما يرد قولكم أترجعون؟ قالوا: نعهم، قلت: أما قولكهم: حكم الرجال في أمر الله، فإني أقرأ عليكم في كتاب الله أن قد صير الله حكمـه إلى الر جـال في ثمن ربع درهم، فأمر الله تبارك وتعالى أن يحكموا فيه، أرأيت قول الله تبارك وتعالى:يا أيها الذين آمنوا لا تقتلوا الصيد، و أنتم حر م، و من قتله منـكم متعمدا فجزاء مثثل ما قتل مـن النعمم يحكمم بـا ذوا عدل منـكمه (rv)، و كان مـن حكم الله أنه صسيره إلى الرجال يحكهون فيه، و لو شاء لحكم فيه، فجاز من حكم الرجال، أنثدكم بالله أحكم الرجال في صدلاح ذات البين، وحقن دمائهم أفضل أو في أرنب؟ قالوا: بلى، هذا أفضل و في المـر أة وزوجها: إووإن خفتهم شقاق بينهما فابعثوا حكما من أهله

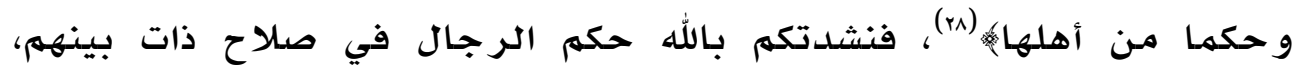
وحقن دمائهم أفضل مـن حكههم في بضع امر أة؟ خرجت من هذه؟ هـ " قالوا: نعمم قلت: و أما قو لكم قاتل ولهم يسب، ولهم يغنهم، أفتسبون أمكمم عائشة، تستحلون منها ما تستحلون مـن غيرها وهي أهكمى فإن قلتهم: إنا نستحل منها مـا نستحل من غيرها فقد كفرته، وإن قلتم: ليست بـأمنا فقد

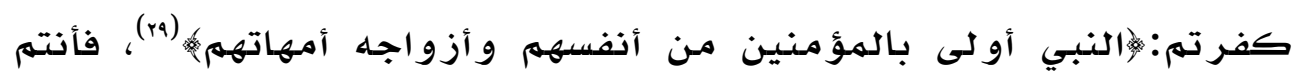
بين ضدلادتين، فأتوا منها بهـر ج، أفخر جت مـن هذه؟ قالوا: نعم، و أما مـحي نفسـه مـن أمير الهؤمنين، فأنا آتيكم بهـا تر ضون، إن نبي الله صلى الله عليـه وسلم يوم الحديبيـة صدالح الهشركين فقال لعلي:"اكتب يـا علي هذا مـا صالح عليه محهمد رسول الله" قالوا: لو نعلهم أنك رسول الله ما قاتلناك فقال رسول الله صلى الله عليه وسلهم: "امـح يا علي اللههم إذك تعلهم أني رسول الله، امح يا علي، واكتب هذا مـا صالتح عليه محهد بن عبد الله" و الله لرسول الله صلى الله عليه وسله خير من علي، وقد محى نفسـه، و لم يكن محوه نفسـه ذلك محاه مـن النبوة، أخرجت من هذه؟، قالوا: نعهم، فرجـ 
منهم ألفان، وخرج سـائرهم، فقتلوا على ضدلاكتهم، فقتلهم الههاجرون

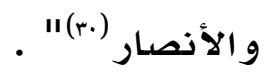

و الحديث بيّن لنا أن أهل البدع لا يحاورهم إلا عالم متتمكن حتى لا يقع في شبههم، وحتى يبيّن لهم الفهم الصحيح لكتاب الله عز و جل كهما فعل ابن عباس رضي الله. 


\section{المبحث الرابع: حوار المخالف غير المسلم \\ الأملب الأول: حوار النبي صلى الله عليه وسله لمشركي مكة.}

لقد بعث النبي صلى الله عليه وسلهم في بيئة عم فيها الشرك، و التقرب لكلأوثان؛ فأمره الله عز وجل بـدعوتهم إلى توحيده وينهاهم عن الشرك كـ بـ فها كان مـن أو لئك القوم إلا أن كذبوه، وناصبيوه العداء؛ فكان يعفو، ويصفح، ويلقاهم بالجميل، ويعرض عليهم الدعوة بوضوح و جلاء، فكان يبتدرهم بالحوار، ووكان يجيب عن إشكالاتهه، وكان ينصت آنهان لههم، ويصغي لهما يقولون، ويأخذ بكل ما تقتضيه أصول الحوار و آدابـه. و مـن الأمثلة على ذلك ما جاء في مححاورته لأهل مكلة في صلح الحديبيـة:

عن البراء قال: لها أحصر النبي -صلى الله عليه وسلهم- عند البيت صالحه أهل مكة على أن يدخلها فيقيهم بها ثلاثا ولا يدخلها إلا بجلبان السـلاح السيف وقرابه، ولا يخرج بأحد معهد مـن أهلها ولا يهـنع أحدا يهكث بها مهـن كان معه، قال لعلى:" اكتب الشرط بينـا بسهم الله الرحهن الرحيهم هذا مـا قاضى عليه محمدل رسول الله، فقال له المشركون: لو نعلهم أذك رسول الله تابعناك و لكن اكتب محهد بن عبد الله، فأمـر عليا أن يمهحاها فقال على: لا والله لا أمحاها، فقال رسول الله -صلى الله عليـ و سلهم: أرذي مكانها، فأراه مكانها فهـحاها، وكتب: ابن عبد الله، فأقام بها ثلاثة أيام، فلها أن كان يوم الثالث قالوا لعلى هذا آخر يوم مـ شرط

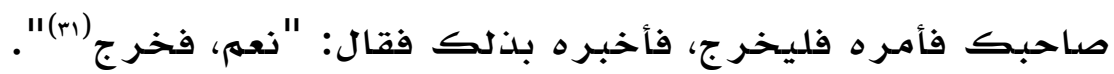
وفي الححديث بيان كلآداب التي ينبغي أن يتحلى بها الهحاور، فلا يضيق و لا يستعجل النتائج، كهم أنه ينبغي للهحاور عند حواره أن يضع هدفين: آني ومستقبلي، كما فعل النبي-صلى الله عليه وسلهم- عند دخول مكة فقبل بشروط (وهذا آني) و خطط بدخول مكة للفتح (وهذا مستقبلي)). الإطلب الثاذي: حوار النبي صلى الله عليه وسليم لليهود.

كان اليهود يبشرون بظهور نبي وأنهم سوف يحاربون معـه، فلها جاءهم مـا عر فوا مـن ظهوره كفروا بـه، وكذبوه، و آذوه، وسحروه، وهموا بقتله، و أر ادوا إطفاء نوره، و لكن الله متهم ذوره و لو كره الكافرون. 
و قد حاورهم النبي صلى الله عليه و سلهم في أكثر من موقف و من ذلك:

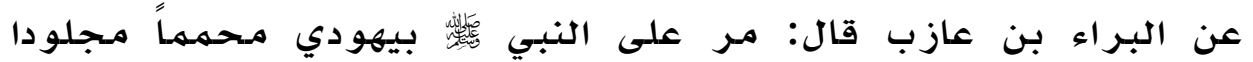
فدعاهم صلى الله عليه و سلم فقال: "هكذا تجدون حد الزاني في كتابكه؟

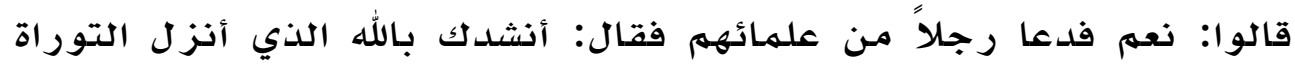
على موسى أهكذا تجدون حد الزاني في كتابكم؟، قال: لا، ولولا أنك نشدتني بهذا لهم أخبر ك نجده الرجهم و لكنـه كثر في أشر افنـا فكنا إذا أخذنا الشريف تر كناه و إذا أخذنا الضعيف أقهنا عليه الحد قلنا: تعالوا فلنجتهـع على شيء نقيهـه على الشريف والوضيـع فجعلنا التحهيهم والجلد مكان أنهان

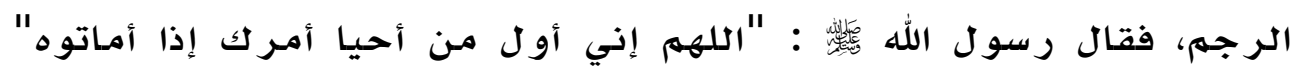

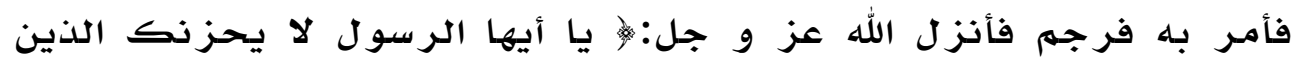

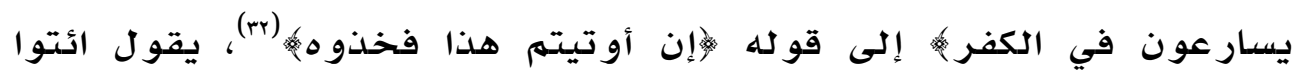

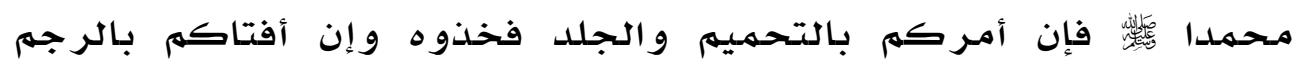

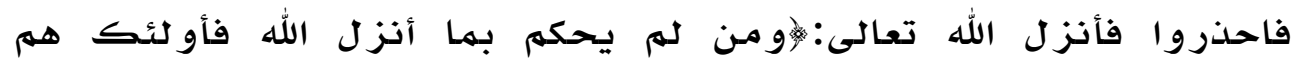

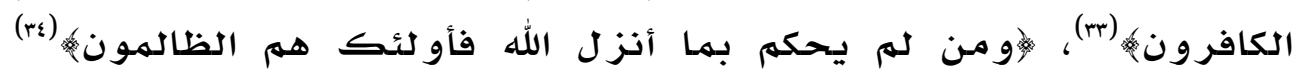

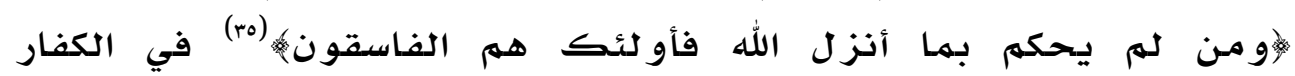
كلهاب(r) "

وفي الححديث أنه ينبغي على الهـحاور إلزام الخهمر بها يعتقده إن كان

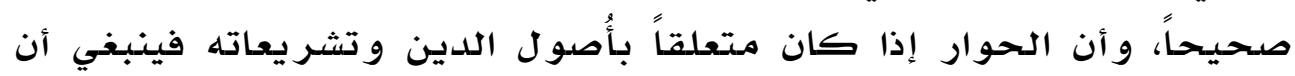

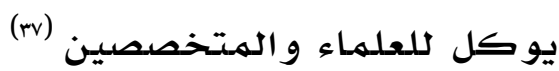
المطلب الثالث: حوار النبي صلى الله عليه وسلم للنصارى: كما أن النبي صلى الله عليه وسلهم حاور اليهود، كذلك حاور النصسارى وون أمثلة ذلك:

مـا أخرجه الترمذي عن عدي بن حاتم قال: "أتيت رسدول الله صلى الله عليه وسلهم وهو جالس في الهسجد فقال القوم: هذا عدي بن حاتم وجئت بغير أمـان و لا كتاب، فلها دفعت إليه أخذ بيدي، وقد كان قال قبل ذلك: إني لأرجو أن يجعل الله يده في يدي، قال: فقام فلقيته امر أة وصدبي معها، فقالا: إن لنا إليك حاجة فقام معهما حتى قضى حاجتهما، ثم أخذ بيدي 
حتى أتى بي داره، فألقت له الوليدة وسادة فجلس عليها، وجلست بين يديه،

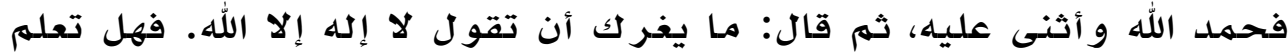

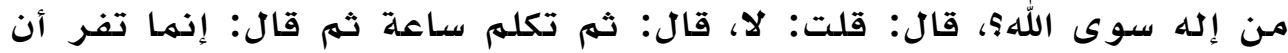

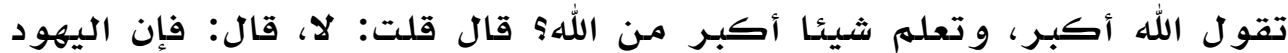
مغضوب عليهم، و إن النصارى ضلال وله قال: قلت: فإني ضيف مسلهم، قال: فر أيت وجهه تبسط فرحاً، قال: ثم أمر بي فأنزلت عند رجلد رجل من الأنصار

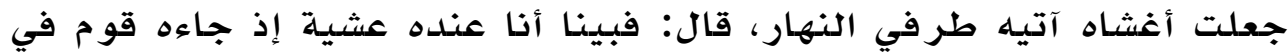

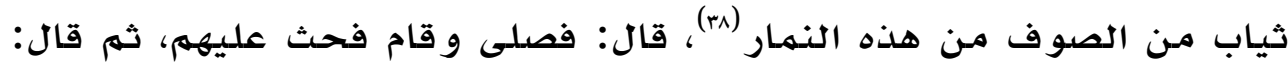
ولو صاع، ولو بنصف صاع، ولو قبضة، ولو ببعض قبضة يقي أحلدكم

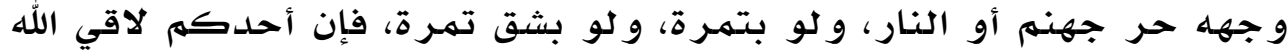

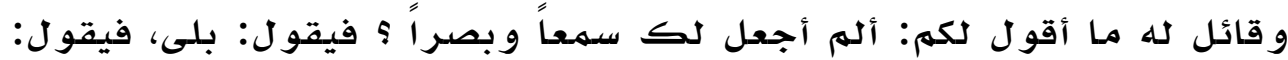

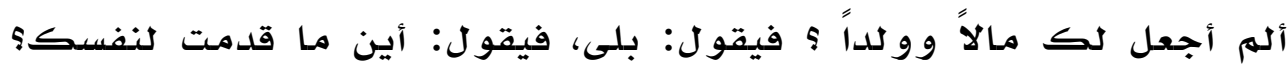
فينظر قدامـه و بعده، و عن يمينـه و عن شماله، ثم لا يجد شيئا يقي بـه و جهه

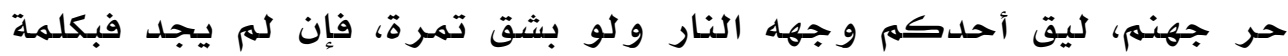
طيبة، فإني لا أخاف عليكم الفاقة، فإن الله ناصر كهم و معطيكم حتى تسير

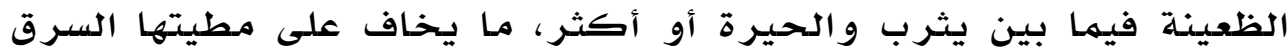

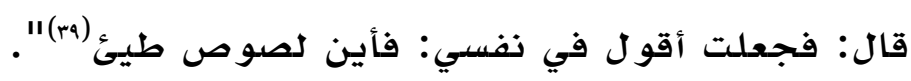

و في حوار النبي صلى الله عليه وسلهم نجد لفتات رائعة في موضوع ألها

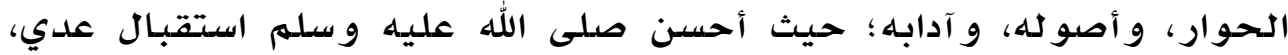
و أنزله منز لته اللائقة به؛ فقرب إليه الوسـادة؛ لعلمها بأنه سيد قومـه؛ فكان لذلك أثره في نفس عدي؛ إذ أدرك أن هذا النبي لا يتكله إلا عن عله إله

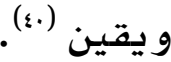


المبحث الخامس: بعض الآداب التي ينبفي مراعاتها في الحوار

الاطلب الأول: إخلاص النية لله عزوجل.

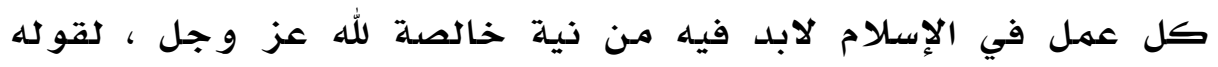

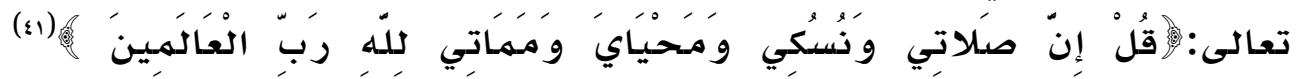

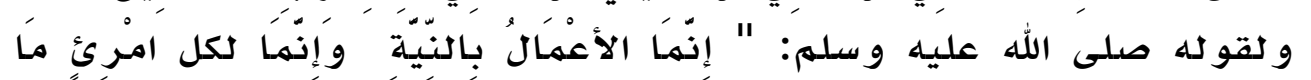

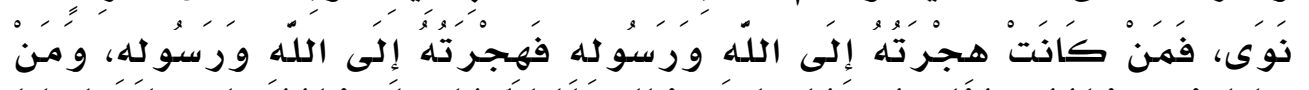

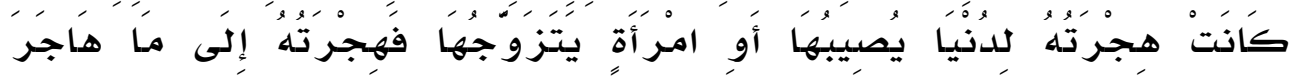

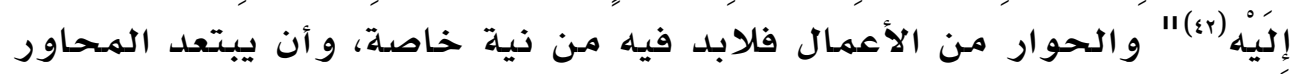

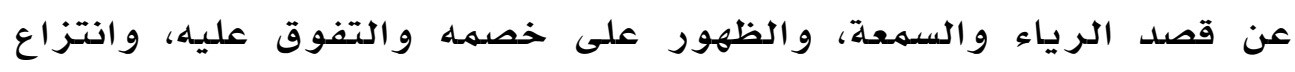

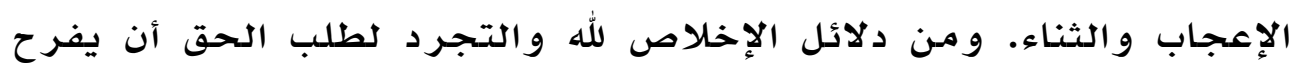

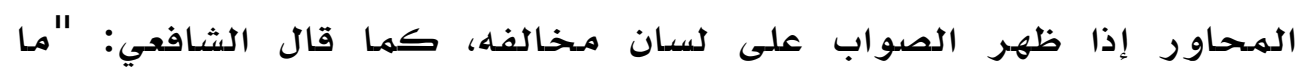

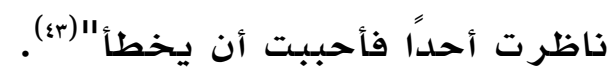

\section{المطلب الثاني: التسلح بالمله.}

العلهم شرط أساس لنجاح الحوار وتحقيق غايته، وبلدونه لا ينجح حوار، و يهلدر الوقت و يضيع الجهد.

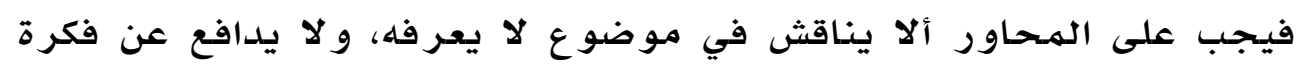

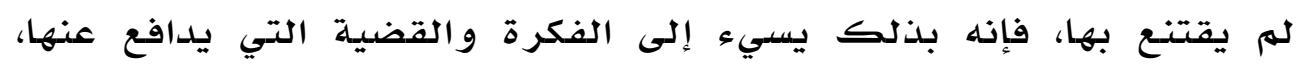

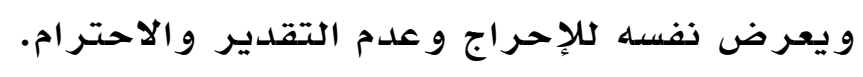

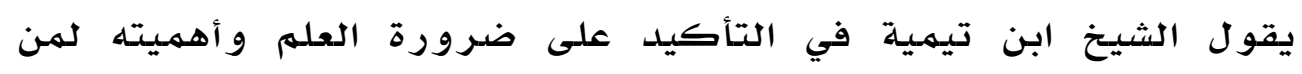

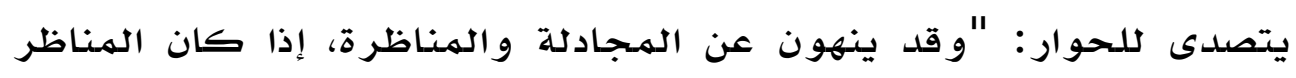

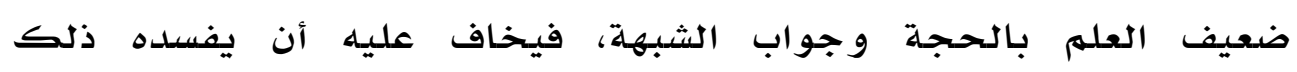

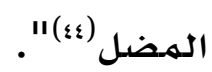

\section{المطلب الثالث: حسن الاستماع وتجنب المقاطعة.}

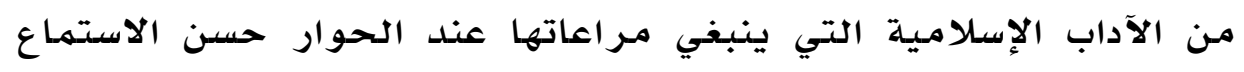

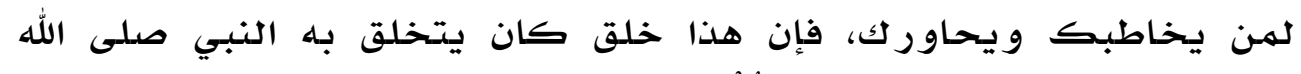

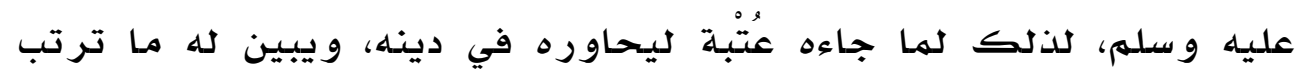

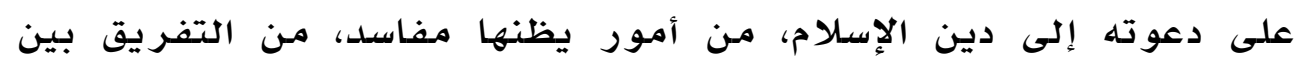


الوالد والولد، وجعل ذلك تسفيها لدين الآباء والأجداد، أنصد له النبي هلى الله عليه و سلهم ثم قال له: "أفرغت يا أبا الوليد"؟ قال: نعم" فاقرأ عليه النبي- صلى الله عليه وسلهم- أوائل سورة فصلت، فكان ذلك سبيًا في تغيير شيء مـن مـوقفه (هـ). المطلب الرابع: العدل والإنصاث.

يجب على الهـحاور أن يكون منصفاً، لأن إنصـاف الخصــم أمسر أسـاسـي

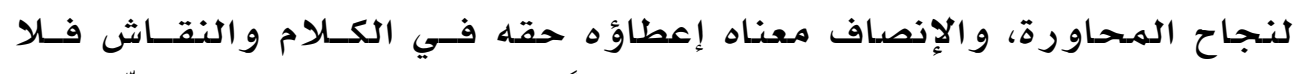
تضييق عليه، و يتر كه ليبسط رأيه و اضحاً، ثم يأخذ الهحاور في رده الذي ينقض قول الآخر أو يعدله حسب سياق الهـحاورة.

و الإنصاف لون مـن العدل الذي أمـرنا بـه حتى مـع من ذخالفهم و نبغضههم

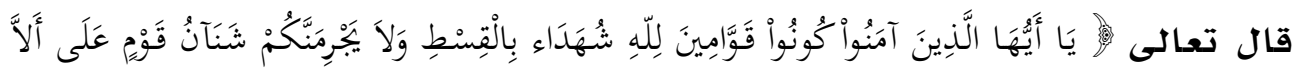

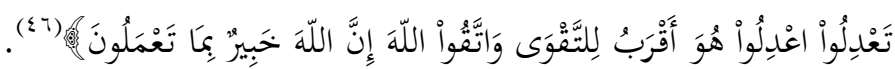

وحين يفتقد الحوار الإنصاف و العدل يفقد الإقناع، بل يُقابل بالسخرية، و من أمثلة ذلك أن قريشاً حين تأكّد لديها أن أبا طالب غيرٌ مسلبمٍ محهداً

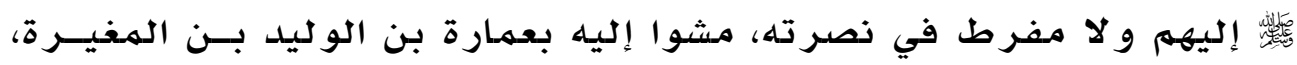

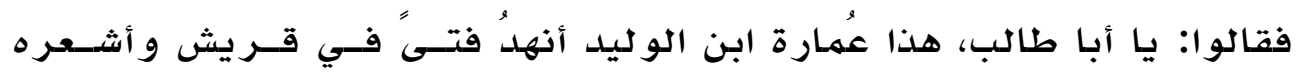
و أجمله، فخذه فلك عقلُه ونُهر ته، و اتخذه و لداً؛ فهو لك، و أسلهم لنـا ابـن أخيك - هذا الذي قد خالف دينك ودين آبائك، ووفـرق جهاعـة قومسك،

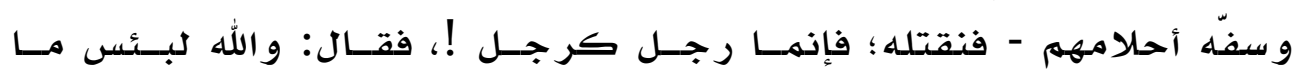
تسو مونتي! أتعطونتي ابنكم أغزوه لكهم، و أعطيكهم ابني تقتلُونه! هــذا و الله

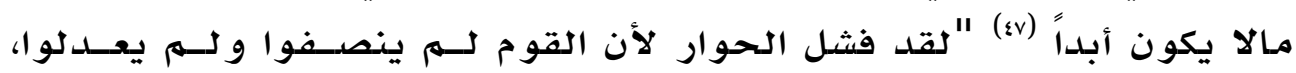

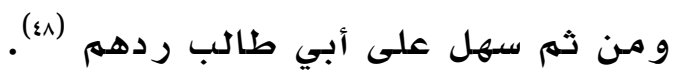

المطلب الخامس: ضبط النفس.

فالهحاور يجب أن يكون حليهاً صبوراً يضبط نفسه فلا يغضب لأتفه سببـ، فإن ذلك يؤدي إلى النفرة منهه، والابتعاد عنه، و الغضبب لا يوصل إلى إقناع الخصهم وهدايته، و إنهما يكون ذلــك بـالحلهم و الصـبـر، و الحلـهم مسـن

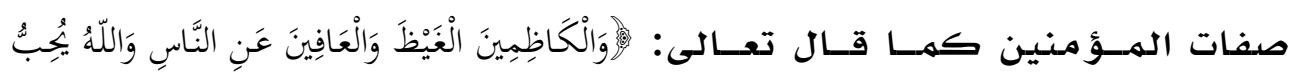




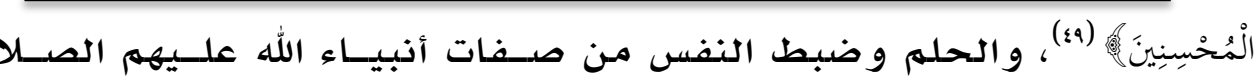

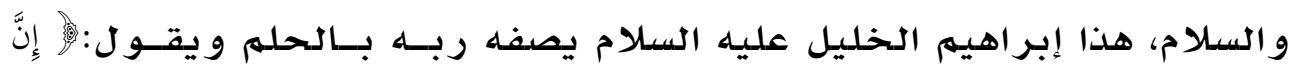

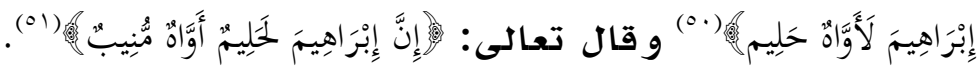

أمًا صفوة الخلق صلى الله عليه وسلهم فقد كان أكثر الخلق حلهاً و ضبطاً للنفس، فيصبر ويصفح ويسامـح ويتجاوز، وكان يأمـر بضبط النفس والابتعاد عن الغضب، بل ويوصي من طلب منـه الوصية بالابتعاد عن الغضب، كها جاء في حديث أبي هريرة رضي الله عنه: أن رجلا قال للنبي

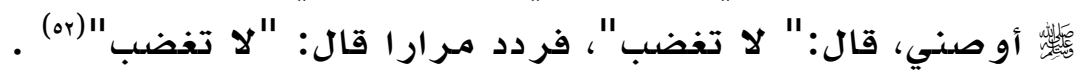
و من أعلى مـراتب ضبط النفس مقابلة الإسـاءة بالإحسان، فإن ذلك له أثر عظيم على الهحاور، وكثير من الذين اهتدوا لهم يهتدوا لعلهم الهحاور

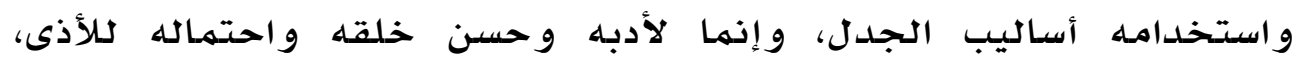
و مقابلته بـالإحسان

\section{الخالقة}

بعد تجو لنـا في البحث تعرفنـا فيـه علـى معنـى الحــوار، ومــن هـو الهقصدود بـالهـخالف فيه، ووضـربنا فيه بعض الأمثلـة لحــوارات أهـلـل الســـة، و أكدنا أنهم مـع نشوب الخلافات بينههم إلى أن هذه الخلافات لهم تـؤد إلـى إلى

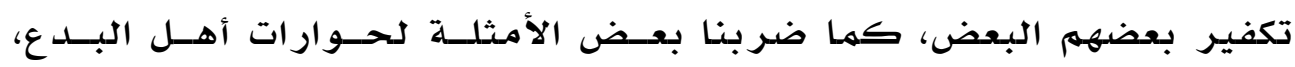
و أكدنا أنه لأبدا أن يحاورهم أهل العلم حتى لا يقع الجـاهل فـي شـبههم. ثم بعد ذلك ذكر ذا أمثلة لحوارات النبي صلى الله عليه وسلهم لمشـر كي

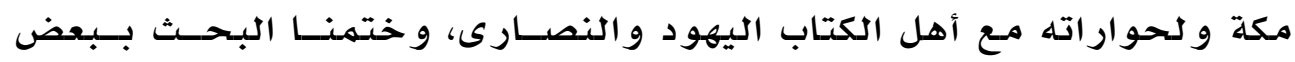
الآداب التي ينبغي أن يتأدب بها الهحاور 


\section{النتائج والتوصيات}

و في ختام البحث نذكر بعض النتائج والتوصيات التي خرجنا بها

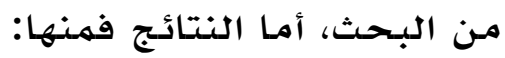

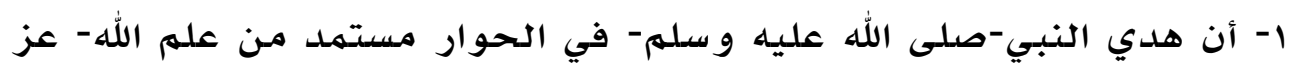

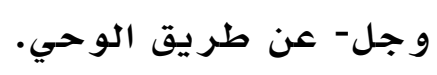

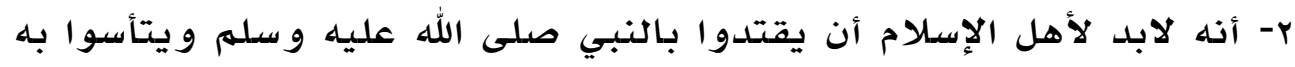

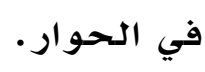

ب- أن تر ك الناس لآداب الحوار التي كان يتبعها النبي صلى الله عليه وسلهم

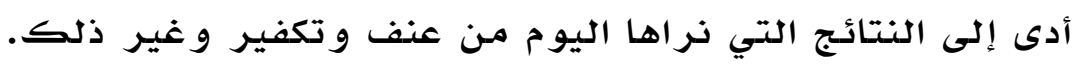

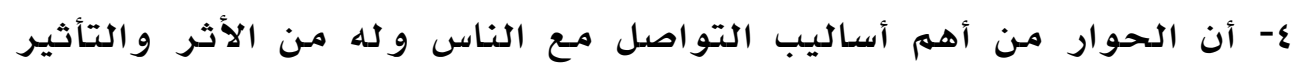

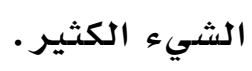

ه- أن الحوار ينبغي أن تكون الغاية منـه الوصول إلى إلى الحق.

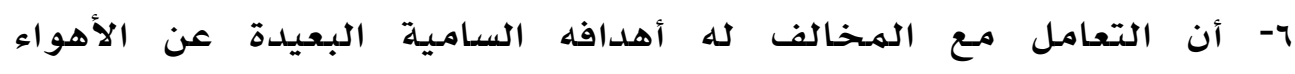
و الأغر اض الثخصية.

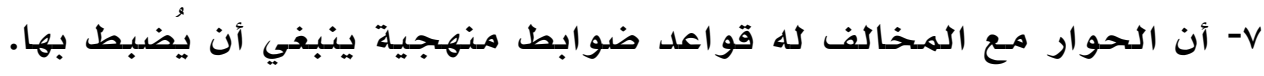

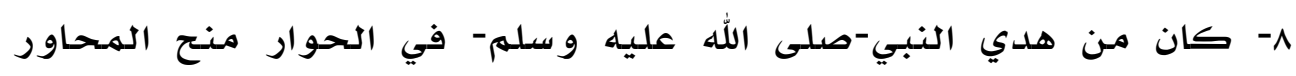

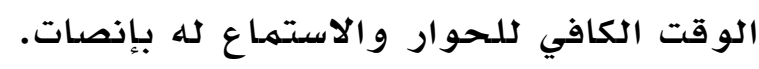

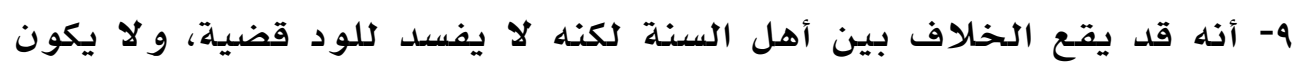
سبباً للقدح بينهم. • ا- معر فة سعة صدور الصحابة عند الاختلاف و التنازع.

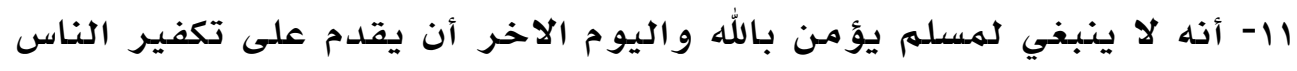

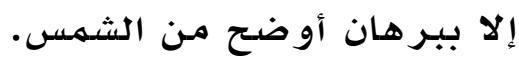

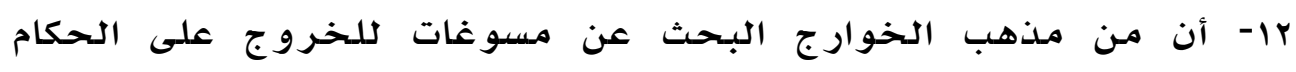

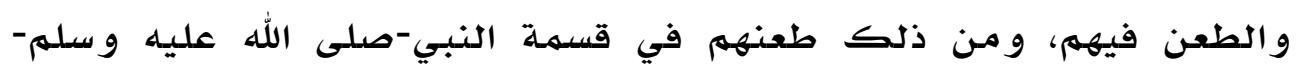

$$
\text { لغنائم حنين. }
$$

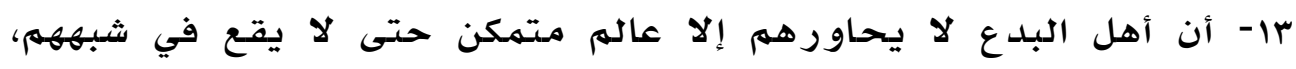

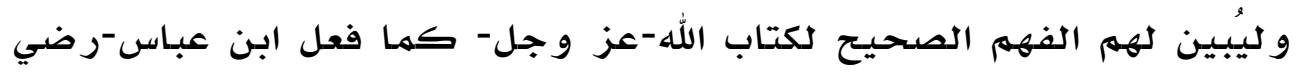

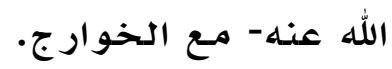


عا- أن المحاور عليه يتحلى بالصبر و أن لا يستعجل النتائج.

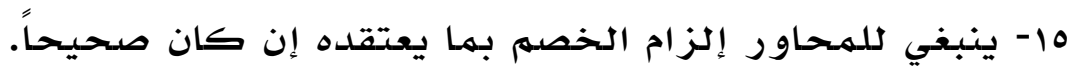

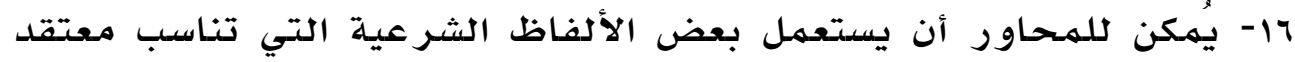

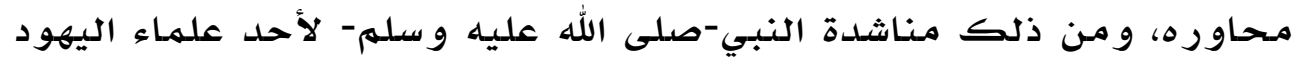

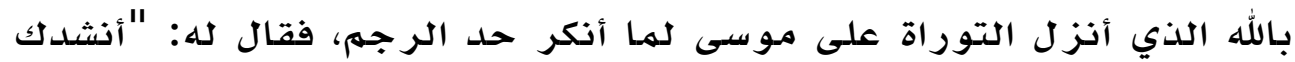

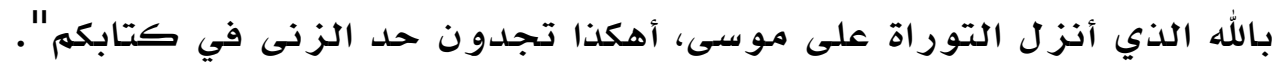

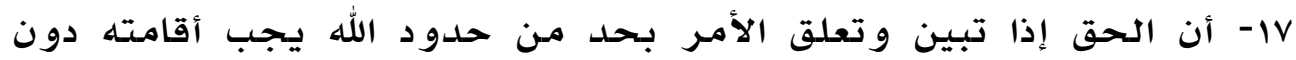

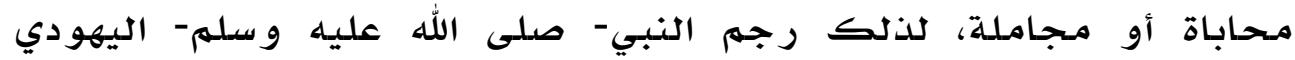

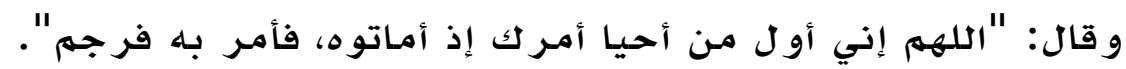

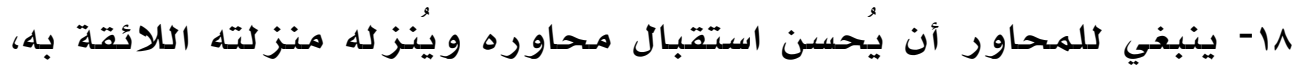

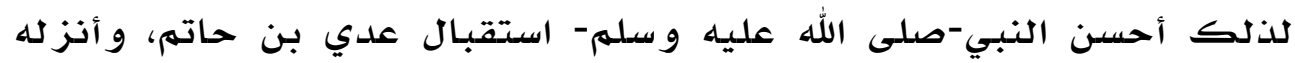

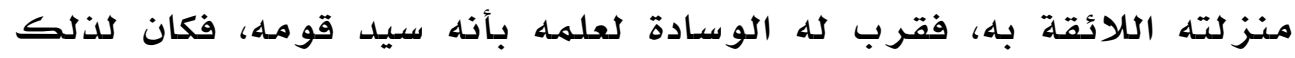
أثره في نفس عدي. 19- أن مـن الآداب التي ينبغي مـراعي فاتها في الحوار إخلاص النية لله- عز وجل. •r- ينبغي للهحاور أن يتسلح بالعلم وأن لا يتحاور في موضوع لا يعرفه، و أن لا يدافع عن فكرة غير مقتنع بها.

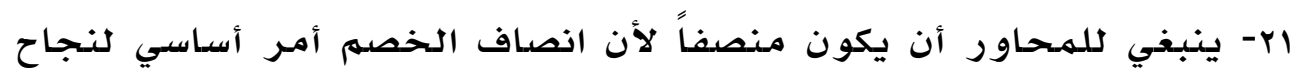

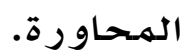

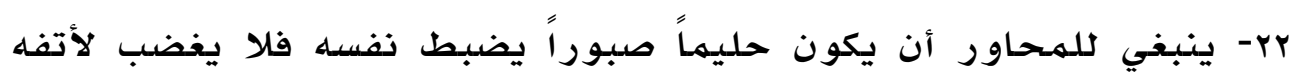

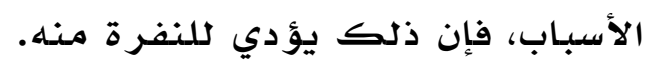

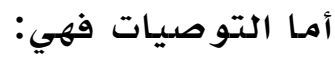
ا- أنه ينبغي أن يتصدئ للحوات فئوار العلماء و الفقهاء.

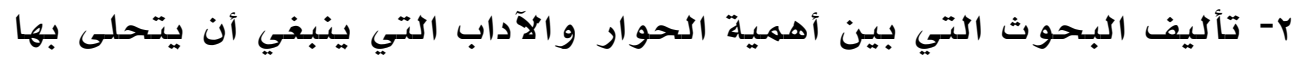
المححاور ب- ضرورة الاطلاع على حوارات النبي صلى الله عليه وسلهم وإخراج

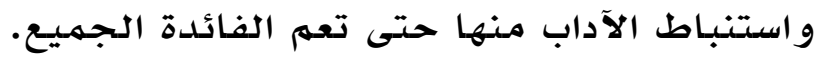


ع- الاستفادة من الوسائل الحديثة في الحوار و تلدريسه لطلاب العلهم و لغير همر.

ه- إقامـة دورات تدريبية للدعاة وأئمسة الهساجد تشتمل على كيفية حوار

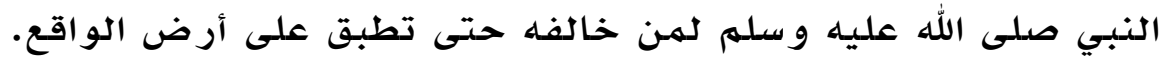

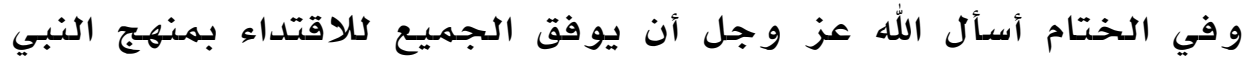

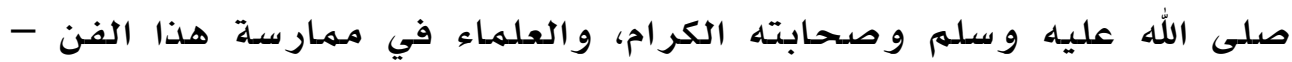

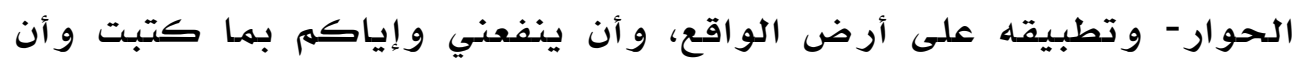
يجعل ذلك في ميزان حسناتنا إنه و لي ذلك الكوان والقادر ان عليه. 


\section{المصادروالمراجع}

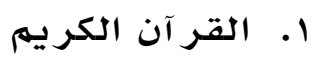

r. الإبانة عن شريعة الفرقة الناجية و مجانبة الفرق المـذمو مـة، تأليف:

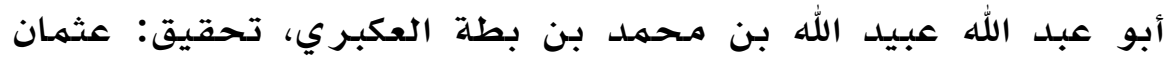

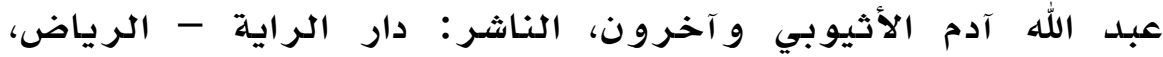

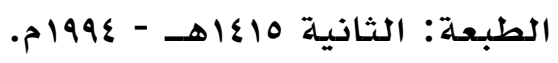

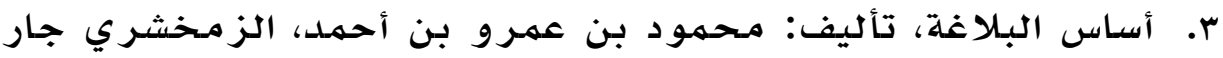

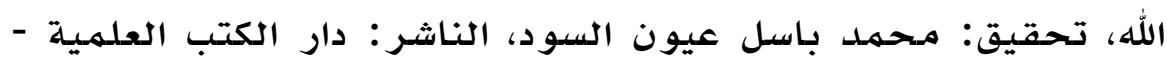

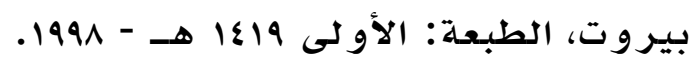

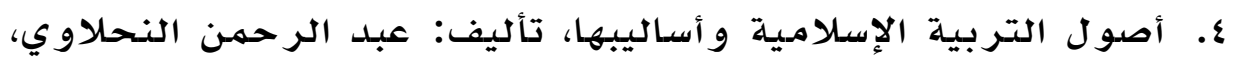

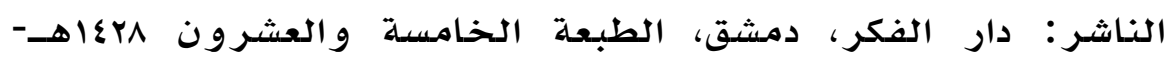

$$
\text { . } r \text { r.? V }
$$

ه. الاعتقاد والهداية إلى سبيل الرشاد على مذهب السلف و أصحاب الحديث، تأليف: أحمد بن الحسين ابن علي ابن موسى الدئ البيهقي،

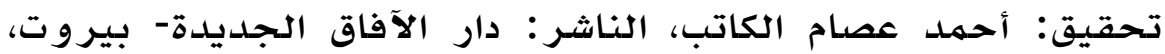

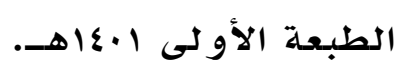

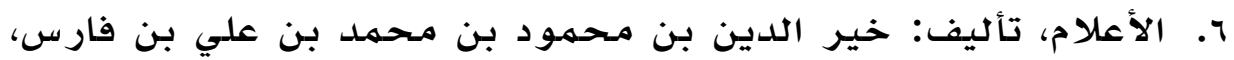

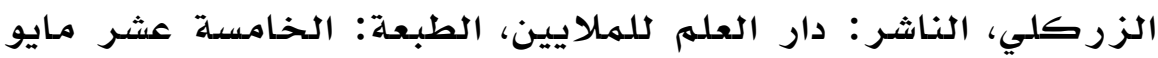

$$
r \cdot r \cdot r
$$

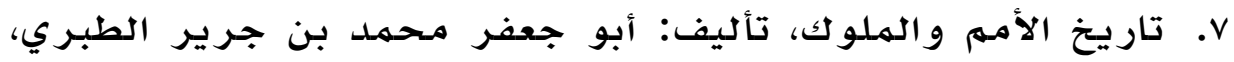

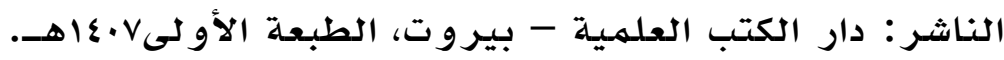

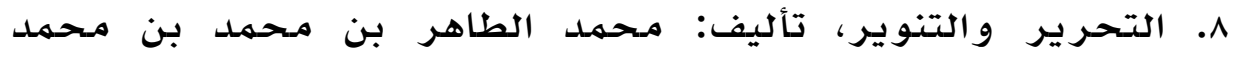

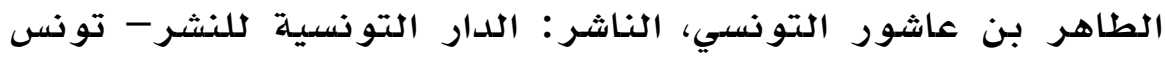
$.0191 \varepsilon$

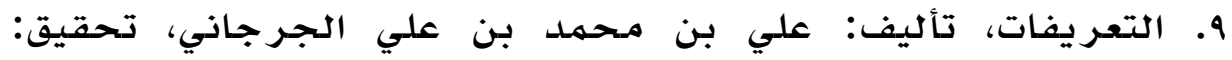

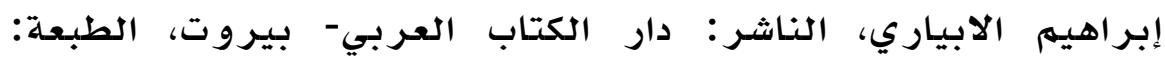

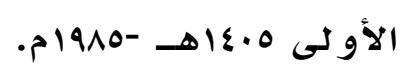


•ا. الحوار آدابـه و تطبيقاته في التربية الإسـلاميـة، تأليف: خالد بن محمد الهغامسي، الناشر: مركز الملك عبد العزيز للحوار

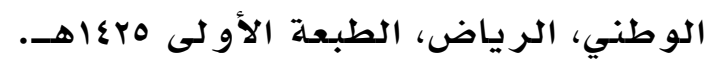

الـ الحوار في السيرة النبويلة، تأليف: الدكستور السيد علي خضر، النـاشر : رابطة العالم الإسلامي، بدون رقم طبعة. ץا. درء تعارض العقل والنقل، تأليف: تقي الدين أبو العبـاس أحمد بن عبد الحليهم ابن عبد السـلام ابن تيهية، تحقيق: الدكتور محمد

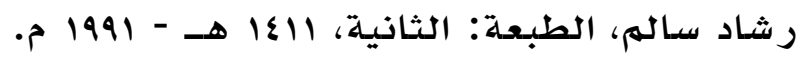

سا. الزاهر في معاني كلهات الناس، تأليف: أبو بكر محمدل بن القاسهم الأنباري، تحقيق: د. حاته صالح الضسامن، الناشر : مؤسسة الرسالة -

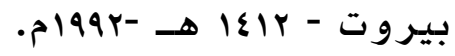

عا. سنن التر مدي، تأليف: محهمد بن عيسى بن سوَّرة الترمدي، تحقيق: أحمد مهمد شـاكر و مححمد فؤاد عبد الباقي، الناشر: مطبعة

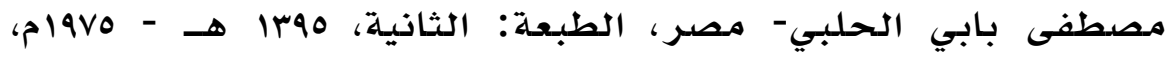
حديث رقمر rqor.

10 السيل الجرار المتدفق على حدائق الأزهار، تأليف: محمدد بن علي بن محمد بن عبد الله الشوكاني اليمني، تحقيق: د. محمدل عبد

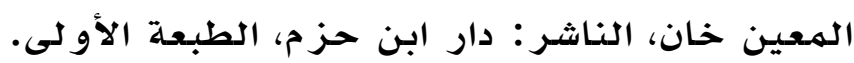
1ا. صحيـح البخاري، تأليف: مـحمد بن إسهاعيل البخاري، تحقيق: د. مصطفى ديب البغا الناشر: دار ابن كثير، بيروت، الطبعة الثالثة

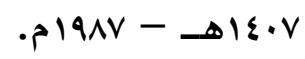

IV صـحيح مسلمه، تأليف: مسلهم بن الحجاج النيسابوري، تحقيق: محمد فؤاد عبد البـاقي، النـاشـر: دار إحيـاء التراث العربي، بيروت، حديث

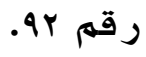

11. غريب الحديث، تأليف: أبو إسحاق إبراهيم بن إسحاق بن إبراهيهم بن بشير البغدادي الحربي، تحقيق: سليهان بن إبراهيهم بن محهمد العايد، الناشر: مـركز البحث العلمي و إحياء التراث الإسلامي

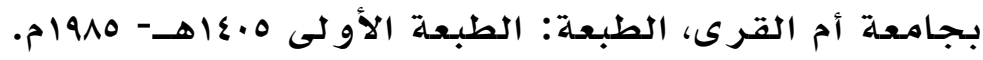


19. غريب الحديث، تأليف: أبو الفرج عبد الرحمن بن علي بن محمد بن الجوزي، تحقيق: د. عبد الهعطي أمين قلعجي، الناشر : دار

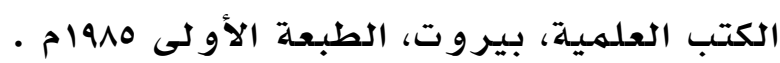

•r. غريب الحديث، تأليف: القاسهم بن سلام الهروي أبو عبيد، تحقيق: د. محمهد عبد الهعيد خان، الناشر : دار الكتاب العربي - بيروت،

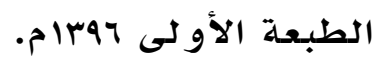
اب. فقه الحوار مـع الهـخالف، تأليف: فتحي عبلد الله الهوصدي، الناشـر:

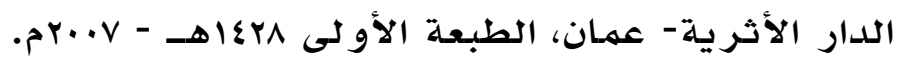

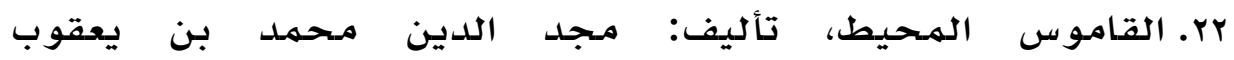
الفيروزآبادي، تحقيق: محمد نعيهم العرقسوُوي، الناشر: مكتب تحقيق التراث في مؤسسة الرسالة - بيروت، الطبعة: الثامنـة بrعا هـ - ه - ه

سז. كسان العرب لابن منظور، تأليف: محمد بن مكرم بن على أبو الفضل، جمال الدين ابن منظور، الناشر: دار صادر - بيروت،

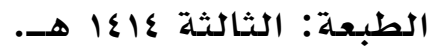

عץ. مسند أحمد، تأليف: الإمـام أحمد بن محمدل بن حنبل، تحقيق: السيد أبو الهعاطي النوري، الناشر: عالم الكتب، بيروت، الطبعة الأولى

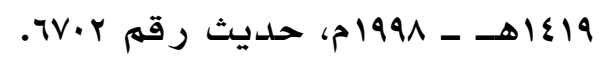
هץ. معجم مقاييس اللغة، تأليف: أبو الحسين أحمد بن فارس بن زكريا، تحقيق: عبد السـلام محمدد هارون، الناشر: دار الفكر-

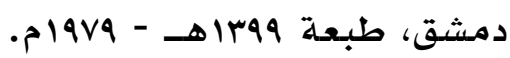

جץ. المـلل و النحل، تأليف: أبو الفتح مـحمد بن عبد الكريهم بن أبى بكر أحمد الشهر ستاني، تحقيق: محمد سيد كيلاني الناشر : الناشر : دار

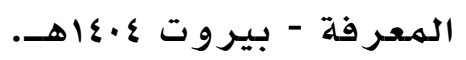
TV السعادات المبارك بن محمدد ابن الأثير الجزري، تحقيق: طاهر

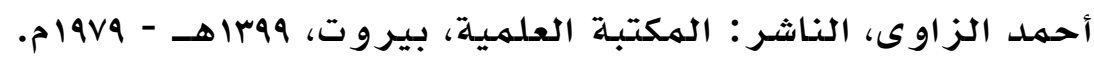




\section{الهواهش}

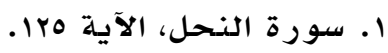

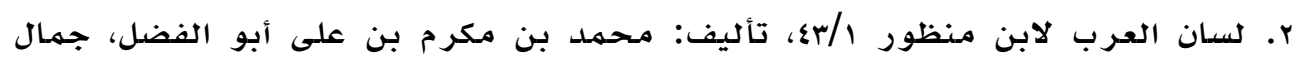

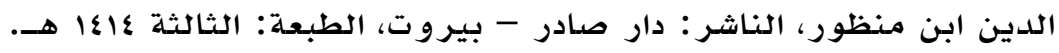

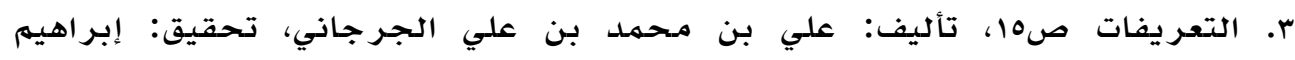

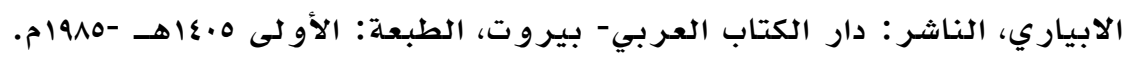

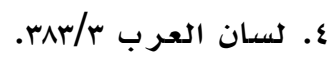

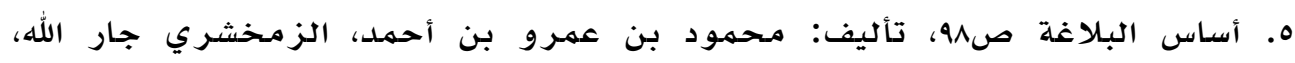

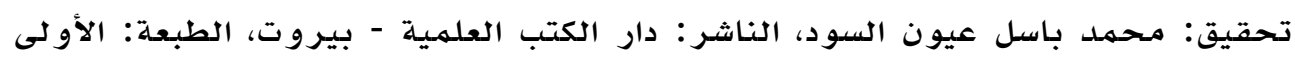
$.1991-$ - هـ 1 ه

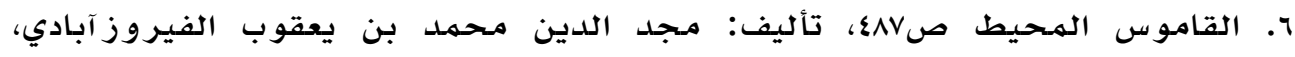

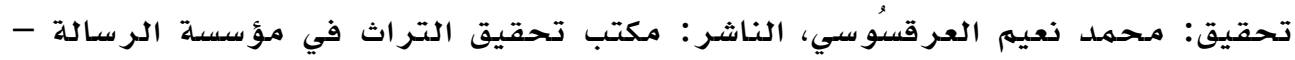

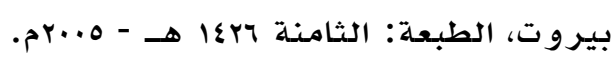

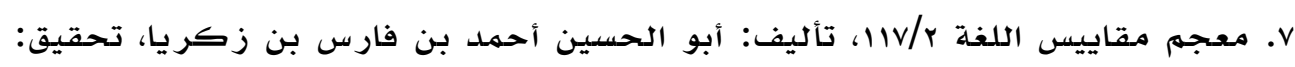

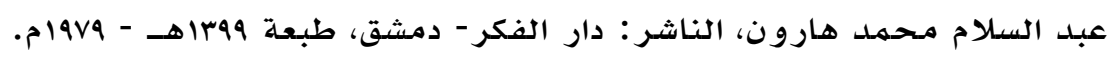
^. ابن عاشور: هو محمد الطاهر بن عاشور: رئيس المفتين المالكيين بتونس وهن وشيخ

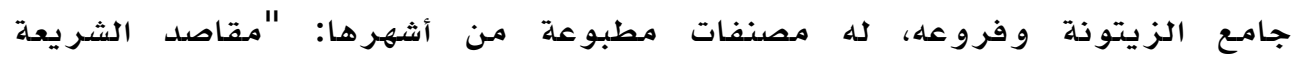
الإسـلامية" و "التحرير و التنوير " في تفسير القر آن، صدر مندر منه عشرة أجزاء توفي سنة

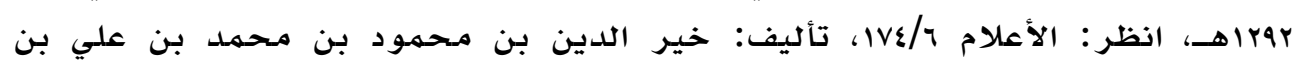

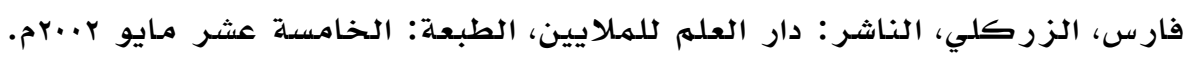

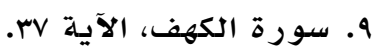

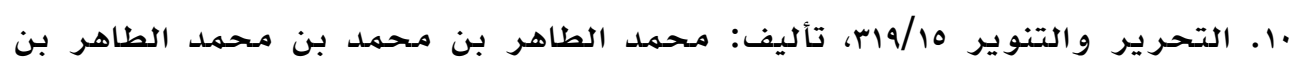

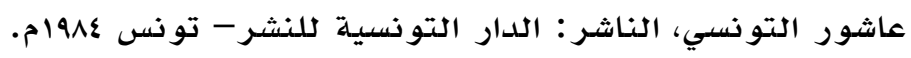

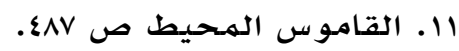

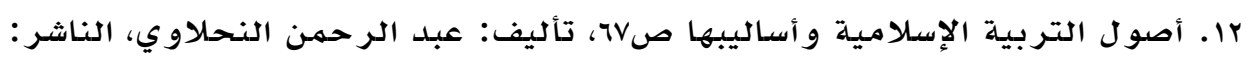

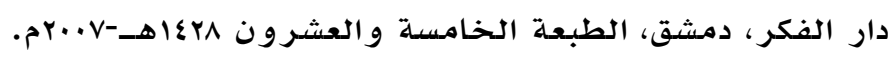

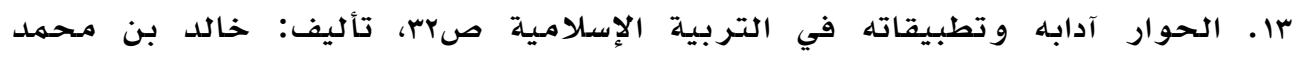

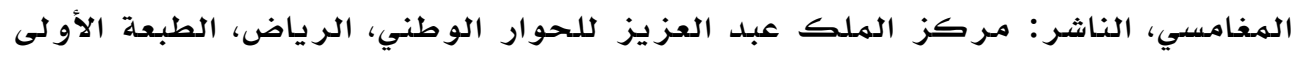


عا. غامر : أي: خاصهم غيره، غريب الحديث r/rآr، تأليف: أبو الفرج عبد الرحمن بن علي بن محمد بن الجوزي، تحقيق: د. عبد الهعطي أمين قلعجي، الناشر: دار الكتب

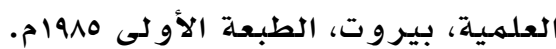

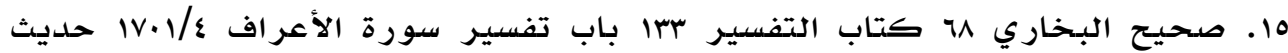
رقم عَبع، تأليف: محممد بن إسهاعيل البخاري، تحقيق: د. مصطفى ديب البغا الناشر:

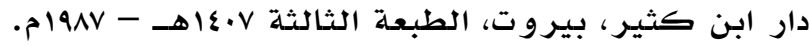
17. حمر النعهم: النعهم الإبل وحمر ها: كر امها و أعلاها منزلة لة الزاهر في معاني كلمات الناس ץ/rسr، تأليف: أبو بكر محمد بن القاسهم الأنباري، تحقيق: د. حاتم صالح الضامـن،

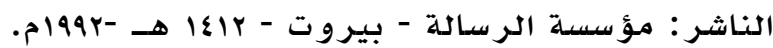

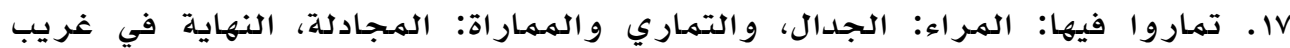

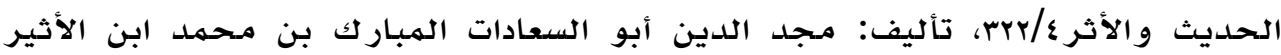
الجزري، تحقيق: طاهر أحمد الزاوى، الناشر: المكتبة العلمية، بيروت، وهاهــ . plava

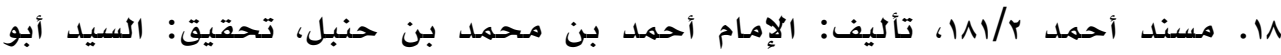

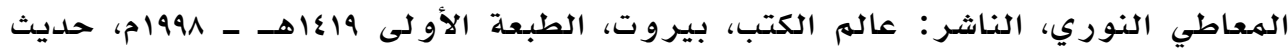
رقم ب.r.

19. الإمام الشوكاني: هو مـحمد بن علي بن محمد بن عبد الله، قاض من فضلاء

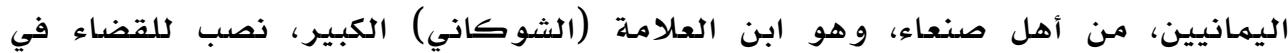

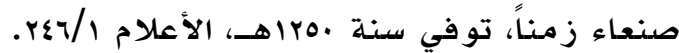
•r. السيل الجرار المتدفق على حدائق الأزهار ص هVA، تأليف: محمد بن علي بن محمد بن عبد الله الشوكاني اليمني، تحقيق: د. محمدد عبد الهعين خان، الناشر : دار ابن حزم،

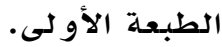

اب. الخوارج: هم كل من خرج على الإمام الحق الذي اتفقت الجماعة عليه يسهى

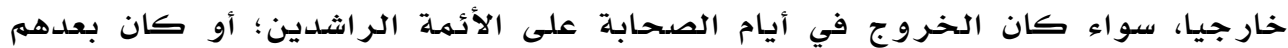

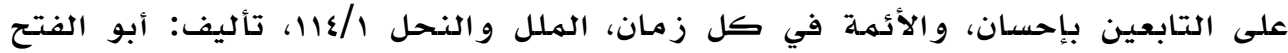
محمدد بن عبد الكريم بن أبى بكر أحمد الشهرستاني، تحقيق: محمدد سيد كيلاني

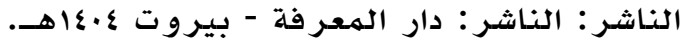

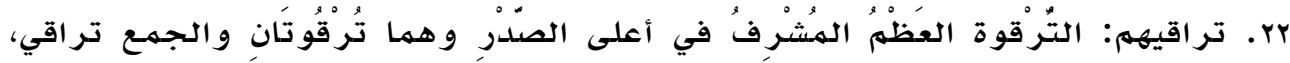

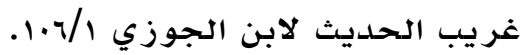

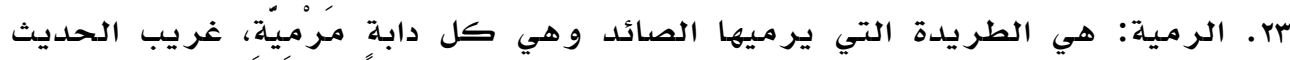

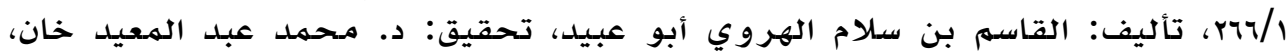
الناشر : دار الكتاب العربي - بيروت، الطبعة الأولى بهمام. 


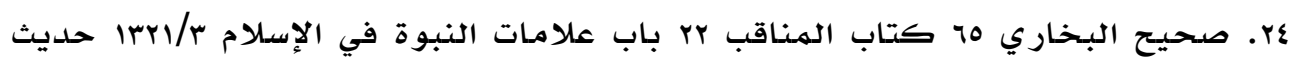
رقم عاءז.

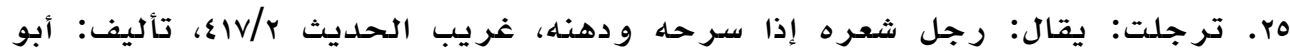
إسحاق إبر اهيم بن إسحاق بن إبر اهيم بن بشير البغدادي الحربي، تحقيق: سليمان بن

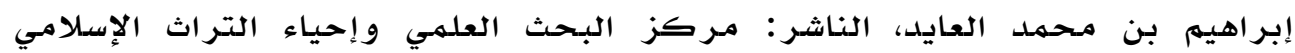

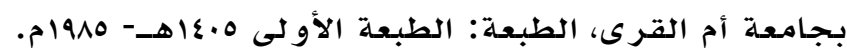

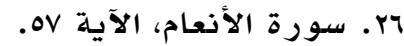
VV

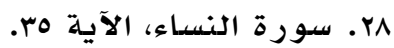

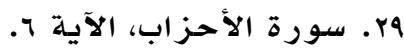

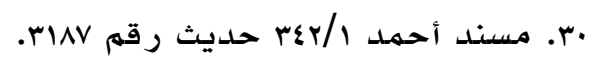

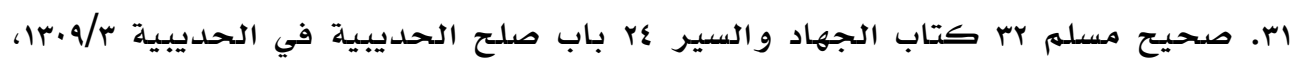

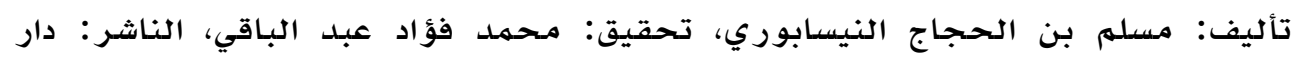

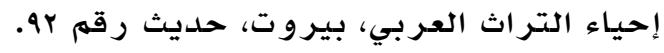

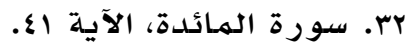

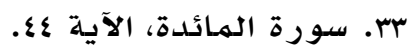

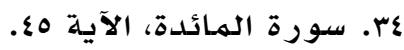

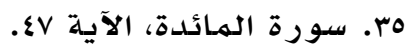

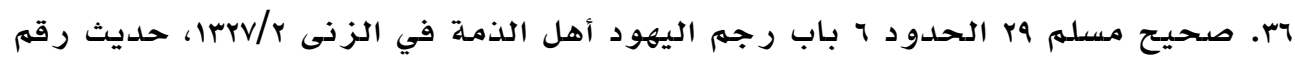
. .

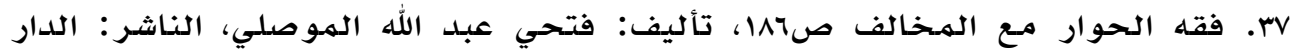

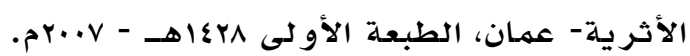

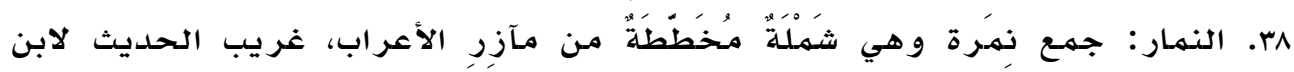

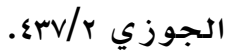

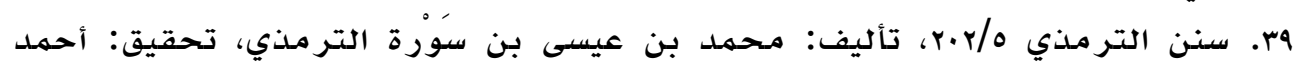

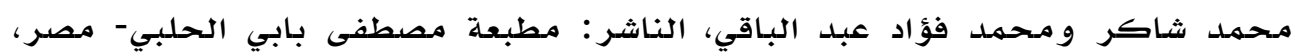

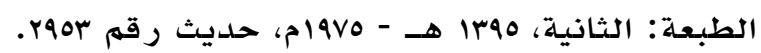
•ع. الحوار في السيرة النبوية صلهیl، تأليف: الدكـتور السيد علي خضر، الطبعة:

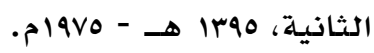

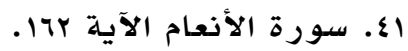


بـ. صديح البخاري ا كتاب بلدء الوحي 1 كيف كان بلدء الوحي لرسول الله صلى الله

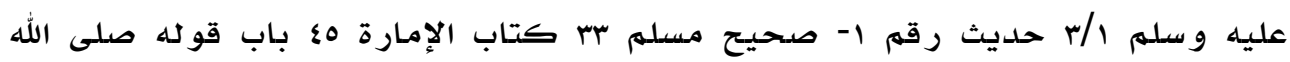

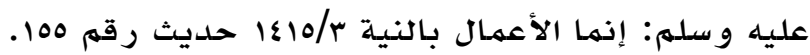

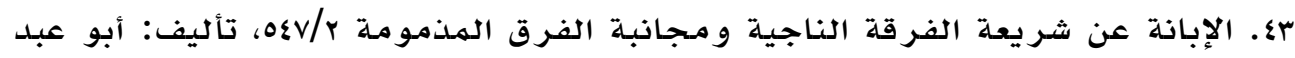
الله عبيد الله بن محمدد بن بطة العكبري، تحقيق: عثمان عبد الله آدم الأثيوبي و آخرون،

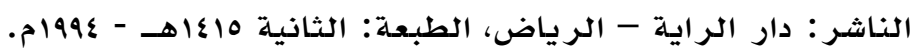

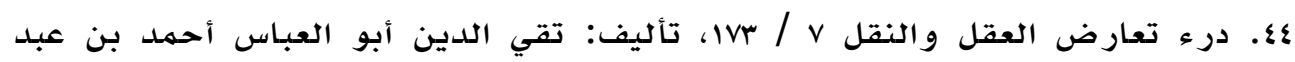
الحليم بن عبد السلام بن تيمية، تحقيق: الدكتور محمد رشاد ساله، الطبعة: الثانية،

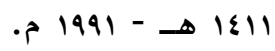
هـ. انظر كتاب الاعتقاد و الهداية إلى سبيل الرشاد على مذهب السلف و أصحاب الحديث

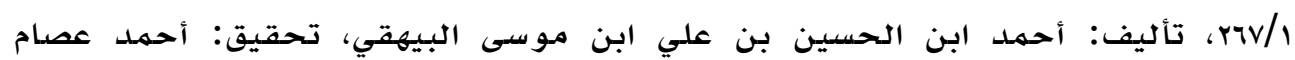

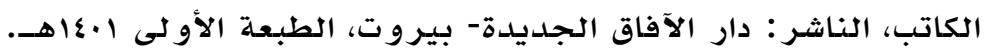

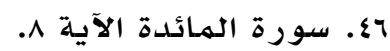

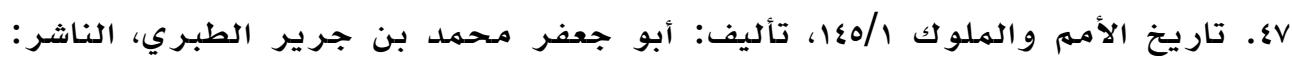

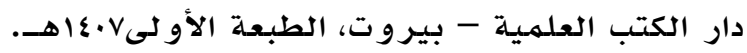

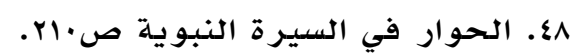

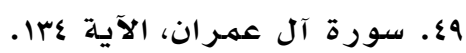

0.

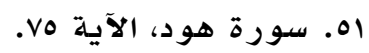

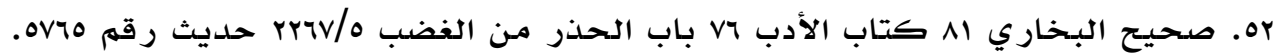

